\title{
THE ASSOCIATION BETWEEN PERCEIVED DISCRIMINATION AND MENTAL HEALTH OUTCOMES OF AFRICAN-AMERICAN COLLEGE STUDENTS: UNDERSTANDING THE ROLE OF PSYCHO-CULTURAL COPING RESOURCES IN INHIBITING STRESS
}

\begin{tabular}{c} 
A Dissertation \\
Presented to \\
The Faculty of the Curry School of Education \\
University of Virginia \\
In Partial Fulfillment \\
of the Requirements for the Degree \\
Doctor of Philosophy \\
\hline by
\end{tabular}

Tanya Maricima Nichols

B.A., Loyola College in Maryland, 2002

M.A. Loyola College in Maryland, 2006

M.Ed., University of Virginia, 2009

August 2014 
(C) Copyright by

Tanya Maricima Nichols

All Rights Reserved

August 2014 


\section{ABSTRACT}

Advisor: JOANNA LEE WILLIAMS 


\author{
Clinical Psychology \\ Curry School of Education \\ University of Virginia \\ Charlottesville, Virginia
}

\begin{abstract}
APPROVAL OF THE DISSERTATION
This dissertation, The Association Between Perceived Discrimination and Mental Health Outcomes of African-American College Students: Understanding the Role of Psycho-Cultural Resources in Inhibiting Stress, has been approved by the Graduate Faculty of the Curry School of Education in partial fulfillment of the requirements for the degree of Doctor of Philosophy.
\end{abstract}

Joanna Lee Williams, Ph.D. Chair

Ronald E. Reeve, Ph.D.

Antoinette R. Thomas, Ph.D.

Heather D. Wathington, Ph.D. 


\section{DEDICATION}

I dedicate this dissertation to my beloved mother, Elaine Leisha Newby, who was a loving and supportive "Mommy". Thank you for your years of love, sacrifice, and prayers which have made me the woman that I am today and have afforded me this great educational opportunity. I will always love you, Mommy. 


\section{ACKNOWLEDGEMENTS}

I would like to thank my Lord and Savior Jesus Christ for this professional calling and for guiding me through my pursuit of becoming a Clinical Psychologist. I am very thankful for my dissertation chair, Dr. Joanna Lee Williams, for her mentorship, guidance, and instruction throughout this dissertation process. I also appreciate the support and feedback from my dissertation committee members, Dr. Ronald Reeve, Dr. Antoinette Thomas, and Dr. Heather Wathington. Thank you for your time and contributions to my scholarship.

I am also forever grateful for my prayerful community of family and friends who have supported me through my Ph.D. - "Purpose He Destined" - doctoral degree journey. I am grateful for my relatives in the United States, Jamaica, United Kingdom, Canada, and the Grand Cayman Islands for their love and prayers during this academic season. I would like to express my deepest appreciation to my best friend, Dr. Patrick Elliot Alexander. You have been my prayer partner and my spiritual strength throughout this dissertation completion journey. Thank you for your faith in me, encouragement, support, and love during this "Strong Finish" season.

I am also grateful for the support of my spiritual sisterhood. Tamika Y. Richeson, thank you for your genuine friendship and for treating me like a true sister. I appreciate the spirit-filled, weekly empowering telephone conversations that we have had since our divine "match" through the University of Virginia Mentoring Institute. I am also grateful for your invitation to participate in the Righteous Writers-Sanctified Scribes (RWSS) dissertation writing group and to attend our very productive dissertation retreat in Maryland. Additionally, I thank you for repeatedly welcoming me into your family and 
your home. I also want to express my sincere thanks to Dr. Lugenia "Genia" Small for your abundant support and prayers throughout this academic journey and season of my life. Genia, I thank you and our prayer group, God's Masterpiece, for your countless prayers, sweet fellowship, and precious friendship over the past 6 years. "Thank you" to Dr. Monae' Johnson for your sisterly love and prayer partnership especially during these final years of my doctoral pursuit. To my dissertation writing accountability partner and friend, Dr. Natalie Perry, thank you for your encouragement and prayers as we both supported each other up to and after our dissertation defenses.

I also wanted to thank the following friends and colleagues whose support and guidance have helped me successfully reach this educational milestone: The University of Virginia Curry School of Education Race Ethnicity and Culture (REC) research lab, Dr. Maurice Apprey and the Office of African-American Affairs, Dr. Cheryl Apprey and the University of Virginia Mentoring Institute, Dr. Thomas McMahon and Yale University/West Haven Mental Health Clinic, Dr. Nancy Suchman, Dr. Derrick Gordon, Dr. Michelle Silva, Dr. Christy Olezeski, Dr. Andrew Case, Dr. Katrina Roundfield, Dr. Tabitha McKinley, Dr. Krystal Lewis, Dr. Gishawn Mance, Dr. Nicole Fischer, Dr. Daniella Teape, Dr. Ayana Jordan, Dr. Debra Nana Yeboa, Adriana DeAmicis, Arwen Wilson, Naila Smith, Elizabeth Ofori \& The Irvington (NJ) Aglow Women's Ministry, Benedict \& Charlene Dorsey and the New Light Church (MD), Marcus \& Ronae' Johnson and the New Harvest Ministries (MD), Gateway Christian Fellowship (CT), First Presbyterian Church (NJ), Inga \& Maxim Duvalsaint, Noelina \& Alvin Collins, Janelle Gumbs, Tammy Gee, Tedeisha Rowe, and Sherrell Hendrix. 
I celebrate this achievement with each of you and also my Afro-Caribbean and African-American forefathers and foremothers who tirelessly fought for my personal and educational freedom as a woman of the African Diaspora. Because of your sacrificial love and commitment to my professional, spiritual, and personal well-being, this Purpose He Destined - Ph.D. academic achievement has been possible. I am deeply grateful for all that you have done for me to attain a dream I had as a 14 year old girl from Newark, New Jersey — to become a Clinical Psychologist. My dream is now a reality. I love you all and may God bless you always. 


\section{TABLE OF CONTENTS}

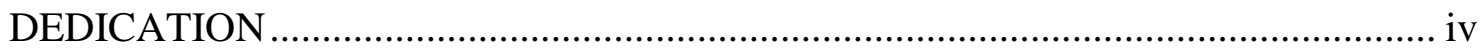

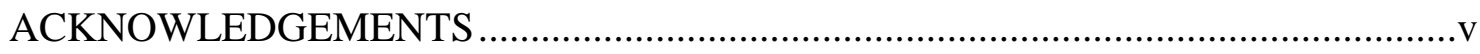

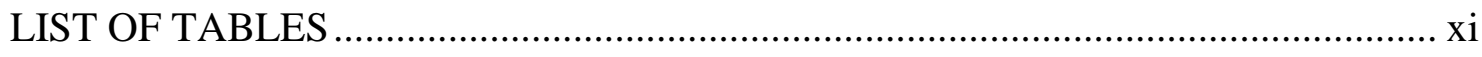

LIST OF FIGURES .................................................................................

\section{CHAPTER}

I. STATEMENT OF THE PROBLEM ................................................

II. REVIEW OF THE LITERATURE ...............................................6

Racial Discrimination and African Americans .......................................6

Discrimination and Mental Health.........................................................

Contextual Models of Racial Discrimination ........................................11

African Americans' Coping with Racial Discrimination............................15

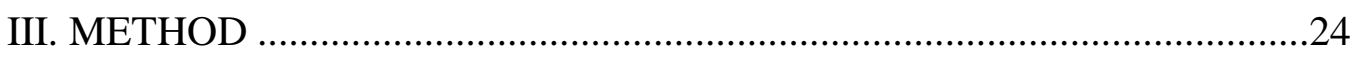

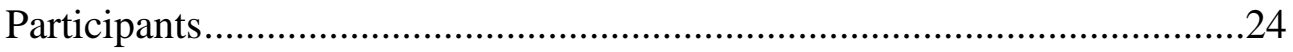

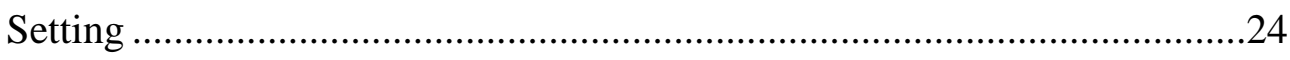

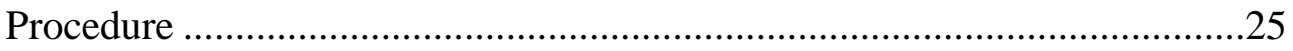

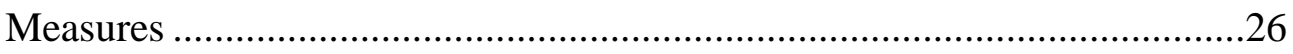

College Racial Discrimination ......................................................26

Psychological Resources ........................................................26

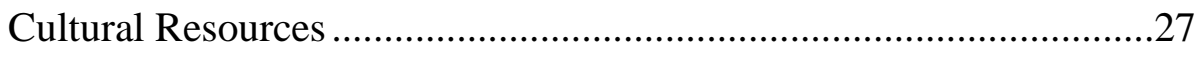

Mental Health Outcomes .......................................................28 


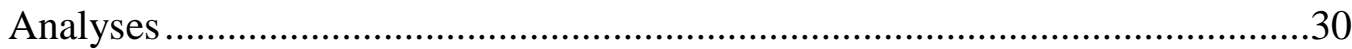

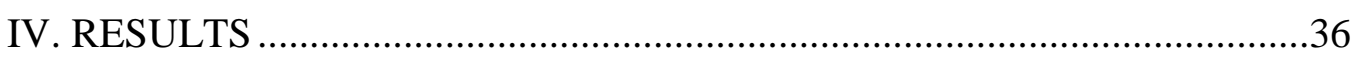

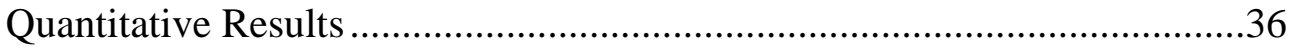

Qualitative Results .......................................................................40

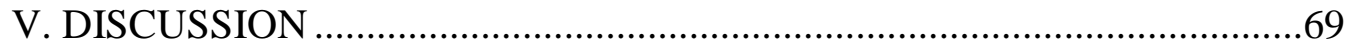

Methodological Strengths and Weaknesses..........................................84

Implications and Conclusions ......................................................90

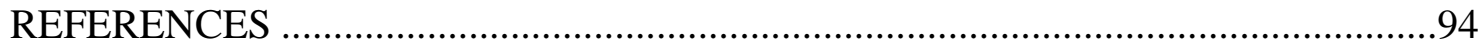

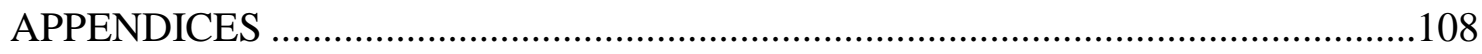




\section{LIST OF TABLES}

TABLE

Page

1. Summary of Intercorrelations of Demographic, Predictor, and Outcome Variables ......38

2. Summary of Intercorrelations of Demographic, Predictor, and Outcome Variables ......39 


\section{LIST OF FIGURES}

FIGURE $\quad$ Page

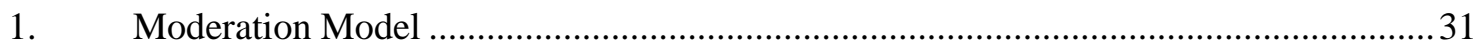

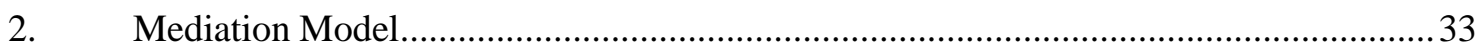




\section{CHAPTER I}

\section{Statement of the Problem}

Empirical evidence suggests that African-Americans living in the United States are at-risk for decreased psychological and physical well-being (Williams \& WilliamsMorris, 2000). Moreover, the health consequences of this increased risk can be exacerbated by daily encounters with racial discrimination (Clark, Anderson, Clark, \& Williams, 1999). Due to their "stigmatized social status, racial minorities [including African-Americans] will experience higher levels of [such] unfair treatment" (Williams \& Williams-Morris, 2000, p.10). Research has indicated that the prevalence rate for reporting a major form of discrimination across one's lifetime and day-to-day discrimination as a frequent occurrence is approximately $50 \%$ (48.9) and 25\% (24.8), respectively, among African-Americans (Kessler, Mickelson, \& Williams, 1999). The combined existing prevalence rates and documented associations between discrimination and mental health highlight its role in the disparate health outcomes of African Americans (Williams \& Mohammed, 2009). These findings suggest that it is imperative to understand how one's racial or ethnic status and experience with such discrimination may place them at greater risk for negative health outcomes (Jackson, Williams, \& Torres, 2003). Furthermore, examining the environment in which African-Americans perceive discrimination may help to further contextualize the particular settings in which 
such groups are prone to encounter racial discrimination leading to increased psychological and physical illnesses.

One context where African-Americans are likely to encounter more discrimination than their peers is at predominantly White colleges and universities (Smedley, Myers, \& Harrell, 1993). It has been noted that minority students such as African-Americans are more likely to attend predominantly White colleges (Hoffman, Llagas, \& Snyder, 2003), yet they continue to have lower graduation rates from these universities compared to predominantly minority institutions. Encounters with racial discrimination on campus are psychological and sociocultural stressors which can lead to the maladjustment of the minority student (Smedley, Myers, \& Harrell, 1993). AfricanAmerican students' experience with college discrimination might explain their unsuccessful matriculation (i.e., $42 \%$ college graduation rate) at many of these schools and the psychosocial challenges that they often face in this environment (Journal of Blacks in Higher Education, 2010). Exposure to college discrimination weakens AfricanAmerican students' sense of connection to their universities and compounds their other stressors (Cabrera \& Nora, 1994; Solórzano, Ceja, \& Yosso, 2000). Moreover, racial discrimination stress can subsequently lead to increased psychological symptoms such as depression, anxiety, and somatic symptoms that African-Americans experience at a predominantly White college (Williams, Jackson, \& Anderson, 1997; Williams \& Mohammed, 2009).

African-Americans in particular have experienced racial microaggressions, or subtle forms of discrimination (Sue, et al., 2007), in the collegiate environment which have led to feelings of "discomfort," "self-doubt," "frustration," and "isolation" 
(Solórzano, Ceja, \& Yosso, 2000, p.10-11) and have contributed to the negative campus racial climate that such students experience. These negative feelings related to AfricanAmerican students' encounters with racial microaggressions on predominantly White campuses have often led to their discouragement about their academic success at these institutions (Solórzano, Ceja, \& Yosso, 2000). African-American students experience a cognitive and emotional overload to not only maintain good academic standings at their predominantly white institution (PWI), but to also carefully manage the overwhelming and stressful racial microaggressive conflicts that they encounter. As a result, the predominantly White university setting becomes a psychologically taxing environment on students that can lead to emotional and physical distress if African-American students are not equipped with adaptive coping strategies (Solórzano, Ceja, \& Yosso, 2000). The potential mechanisms through which perceived discrimination relates to mental health, along with the psychological and cultural (or "psycho-cultural") factors that serve as moderators or mediators of discrimination-related stress, are not well understood (Greer \& Brown, 2011; Utsey, Giesbrecht, Hook, \& Stanard, 2008). Therefore, additional research is needed to determine the role of psychological and cultural resources in mitigating the deleterious effects of racial discrimination experiences on the psychological health of African-Americans attending predominantly White colleges and universities.

The purpose of the present study was to investigate the association between perceived racial discrimination and mental health in a specific environmental context. This relation was examined in a sample of African-American students attending a predominantly White university. Since racial discrimination can result in significant 
psychological distress and can be emotionally burdensome, the personal benefits of attending a predominantly White institution can come with a great psychological cost. Given the documented negative effects that racial discrimination can have on psychological functioning and physical well-being, this research sought to understand how the racial climate of a majority White campus affects the psychological and physical health of African-Americans and the ways in which they cope with the racial stressors that they encounter in this context. This study assessed whether or not psychological (i.e. coping, resiliency) and cultural (i.e., racial identity, ethnic identity) factors are better understood as mediators or moderators in the association between campus-based discrimination and mental health. Understanding how these psycho-cultural factors function in this relation is key to improving the mental and physical well-being of African-Americans who are disproportionately at-risk and vulnerable to poor health outcomes in part due to the inevitable race-related stressors that they face.

For the purposes of this study, the following terms will be used:

Moderation: Statistical moderation is when a relation between a predictor variable and an outcome variable depends on the category or level of a third variable (moderator) (Aiken \& West, 1991). This procedure explains for whom or at what level of another variable does the relation between the predictor and outcome variable occur.

Mediation: Statistical mediation is when the relation between the predictor variable and the outcome variable is explained by a third indirect variable (Baron \& Kenny, 1986). This procedure explains how or the mechanism in which the relation between the predictor variable and outcome variable occurs. 
Racial discrimination: Racial discrimination encompasses "the beliefs, attitudes, institutional arrangements, and acts that tend to denigrate individuals or groups because of phenotypic characteristics or ethnic group affiliation" (Clark et al., 1999, p. 805).

Coping: Coping mechanisms are the psychological strategies that one employs to minimize emotional distress (Gloria, Castellanos, \& Orozco, 2005).

Resiliency: Resiliency is the ability to "recover or bounce back from stress" (Smith, Dalen, Wiggins, Tooley, Christopher, \& Bernard, 2008, p. 194).

Racial Centrality: Racial centrality is a dimension of racial identity defined as the extent to which one's race is central to their identity (Sellers, Rowley, Chavous, Shelton, \& Smith, 1998).

Ethnic Identity: Ethnic Identity is an individual's exploration of their ethnic group, level of commitment, and sense of belonging to their ethnic group (Phinney, 1992; Phinney \& Ong, 2007). 
Chapter II

\section{Review of the Literature}

\section{Racial Discrimination and African-Americans}

Research has documented that racial discrimination remains a significant stressor for many African-Americans (Clark, et al., 1999; Pieterse \& Carter, 2007). To date, there is no sole definition for racial discrimination, but in general, racial discrimination has been broadly understood as differential treatment (which is generally negative) on the basis of race (Williams \& Williams-Morris, 2000, p. 244; Ong, Fuller-Rowell, \& Burrow, 2009, p. 1259). According to Dovidio and Gaertner (1986) racial discrimination is embedded in the "social norms, institutional policies, and cognitive and affective symptoms of White Americans" (p.xi). Moreover, it is believed that present day discrimination is "disguised and covert" and has evolved from the "old fashioned" form in which overt racial hatred and bigotry were consciously and overtly displayed, to a more ambiguous and nebulous form that is more difficult to identify and acknowledge" (Sue et al., 2007, p.272). One form of racial discrimination has been labeled "racial microaggressions," which are "brief and commonplace daily, verbal, behavioral or environmental indignities, whether intentional or unintentional that communicate hostile, derogatory, or negative racial slights and insults toward people of color" (Sue et al., 2007, p.271). Clark and colleagues (1999) have prescribed a definition of racial discrimination that does not exclusively emphasize the relationship between groups that have been 
historically stigmatized/marginalized and those in positions of power, but instead includes both the traditional, overt forms of racial discrimination as well as more subtle and chronic forms of racial discrimination. Therefore, for this study, racial discrimination is operationally defined as "the beliefs, attitudes, institutional arrangements, and acts that tend to denigrate individuals or groups because of phenotypic characteristics or ethnic group affiliation" (Clark et al., 1999, p. 805).

Given the complex nature of racial discrimination, most researchers have commonly focused on the multidimensional nature of its expression and experience. Existing measures have sought to empirically assess the psychosocial and behavioral reactions associated with African American's experiences with racial discrimination (Utsey \& Ponterotto, 1996). Some measures have defined discrimination as racist events that are "negative," "culturally-specific," "acute," or "chronic" events occurring over the course of one's life (Landrine \& Klonoff, 1996, p.146). Others have sought to assess the frequency of exposure to perceived racial discrimination across multiple domains, including "individual," "institutional," "cultural," "behavioral," and "attitudinal" (McNeilly, Anderson, Armstead, et al., 1996, p.154) in addition to the dimensions of emotions, coping behaviors, cognitive appraisals, and stressful effects of the racial discriminatory encounter (Utsey \& Ponterotto, 1996). Lastly, some self-report racial discrimination instruments have sought to gain a deeper understanding of the personal consequences of discrimination by measuring minority group members' perceptions of the impact of discrimination on their individual lives and that of their racial group as a whole (Harrell, 1994). Others have assessed whether individuals have ever experienced racial discrimination or were mistreated because of their race (Jackson, et al., 1996; 
Thompson, 1996; Williams, 2000). More recent measures have sought to examine racial microaggressions targeted at African-Americans including "microinsults" (an action or remark that demeans an individual's racial heritage) and "microinvalidations" (actions that negate the thoughts, feelings, or experiences of a Black individual) (Mercer, ZeiglerHill, Wallace, \& Hayes, 2011, p. 1).

Although there is no one agreed upon operational definition of racial discrimination, the existing measures of racial discrimination have sought to scientifically assess the lived experiences of discrimination encountered by African-Americans. The limitation of these measures, however, is that they exclusively rely on self-reports which reflect participants' perceptions that may be somewhat skewed or even inaccurate, rather than assessing their actual experiences. Hence, these self-reports may be confounded by perceptual biases of the individual and not necessarily consistent with the event that occurred in objective reality. In some ways, self-reports of discrimination are related to individuals' perceptual biases as previous experiences of discrimination not only increase the salience of these events, but also enable individuals to better detect later incidents of racial or ethnic discrimination (Wong, Eccles, \& Sameroff, et al., 2003). Nevertheless, statistically reliable and valid measures of racial discrimination are aimed at assessing the cognitive and affective distress associated with the consensus that African-Americans' encounters with racial discrimination and its effects continue to have deleterious outcomes. Even though there is some tendency to discount perceptions of discrimination as legitimate or even stressful because they involve a subjective component, it is consistent with the stress and coping literature which highlights the importance of the appraisal process (Clark et al., 1999). Most important, despite the criticisms and 
limitations of such measures, its strengths remain as they validate the lived experiences of racial discrimination that African Americans personally encounter.

\section{Discrimination and Mental Health}

Regardless of how it is measured, experiences of racial discrimination can induce physiological and psychological reactions that can lead to adverse changes in mental health (Williams \& Williams-Morris, 2000). A significant amount of research has documented the positive association between perceived discrimination and psychological distress amongst African-Americans (Jackson et al., 1996; Ren, Amuck, \& Williams, 1999; Williams et al., 1997); Williams \& Chung, 2000) and its relationship to mental health outcomes (Sellers, Bonham, Neighbors, \& Amell, 2009). Even when accounting for age, education, income, and skin color, a study by Borrell, Kiefe, Williams, DiezRoux, and Gordon-Larsen (2006) showed that African-American males' and females' perceptions of discrimination were statistically associated with worse mental health outcomes. In a community sample of individuals, African descendants' and recent immigrants' self-reports of discrimination were associated with lower overall psychological well-being and future high levels of psychological distress (Gee, Ryan, Laflamme, \& Holt, 2006). Moreover, a study by Brown et al. (2000) showed that African-Americans with high symptoms of psychological problems experienced racist events as more stressful than did those with low symptoms. Perceived racial discrimination is also negatively associated with life satisfaction (Williams et al., 1997; Jackson et al., 1996; Williams \& Chung, 2000) and well-being factors such as "growth," “mastery," “autonomy,” and "self-acceptance” (Ryff, Keyes, \& Hughes, p. 280). 
Furthermore, studies have shown that racial discrimination is specifically linked to a number of symptoms of stress in African-Americans. Studies have found a positive association between perceived discrimination and depressive symptoms (Schultz et al., 2006) and that everyday discrimination greatly increased the odds of elevated depressive symptoms in samples of African-American men and women (Siefert et al., 2009; Watkins, Hudson, Caldwell, Siefert \& Jackson, 2011). Moreover, Utsey and Ponterotto (1996) have shown that stress experienced by African Americans as a result of their daily encounters with discrimination further related positively to individuals' appraisals of situations in their life as stressful. Research by Landrine and Klonoff (1996) demonstrated a significant correlation between respondents' reports of lifetime and recent racist events and appraisals of events as racist with outcomes such as stress-related psychiatric symptoms, somatic symptoms, feelings of inadequacy, and low self-esteem. Specifically, $17.6 \%$ of the variance in somatic symptoms was accounted for by experiences with racial discrimination in the past year and $17.6 \%$ of the variance of inadequacy was accounted for by the appraisal of the discrimination as stressful. AfricanAmericans with high total stress-related symptoms reported more frequent racial discrimination in the past year and during their lives than did those with low symptoms.

This review of the literature highlights that racial discrimination is adversely related to mental and physical health in African-Americans. These findings underscore that racial discrimination poses a serious and disproportionately greater danger to the psychological well-being of this population. Despite the limitations due to the self-report measures of racial discrimination, the existing data suggest that if racial discrimination is perceived as stressful, then it is likely to have negative mental health consequences. 
Moreover, recognizing that racial discrimination is a significant source of distress that plagues African-Americans is an important precursor to understanding the particular contexts and mechanisms in which these unfortunate chronic discriminatory events occur.

\section{Contextual Models of Racial Discrimination}

While studies have highlighted the positive link between perceptions of discrimination and lessened mental health, limited studies document the influence of environmental context on such outcomes. A number of theories show the importance of the environment on human development and psychosocial outcomes. Bronfenbrenner's (1979) ecological systems framework has emphasized the impact of macrolevel societal influences on the developing person, and, as Garcia Coll and colleagues (1996) note in their integrative model for studying minority youth, racial discrimination can be considered as one of these influences (Garcia Coll et al., 1996). Moreover, Clark and colleagues (1999) have noted that African Americans encounter an excessive amount of environmental factors that may contribute to significant stress reactions. Specifically, one's perception of an environmental stressor as racially discriminatory leads to exacerbated psychological and physiological stress that is influenced by a number of constitutional (i.e., skin tone, occupational status, personal income) socio-demographic (i.e., socioeconomic status, age, gender), and psychological and behavioral factors (i.e., Type A behavior, anger expression-suppression, perceived control). Over time, these stress responses are posited to influence health outcomes. (Clark et al., 1999, p.806).

There is no definite way of predetermining if an environmental stimulus will be perceived as discriminatory by an individual. Nevertheless, the consequences of a lifetime of perceived racial discrimination that occurs in a variety of environmental 
contexts can "potentially contribute to the psychological and physiological sequelae that may be particularly toxic to the well-being of African-Americans" (Clark et al., 1999, p. 807). Hence, according to Clark et al.'s (1999) biopsychosocial model, understanding the general influence of environmental contexts on the mental health of African-Americans is necessary to ultimately determine the factors that may serve to lessen the relationship between perceived discrimination and poor mental health functioning.

There are specific environmental contexts where racial discrimination is often encountered and associated with increased psychosocial distress; for many African American young adults, one of these contexts is the college campus (Smedley et al., 1993). Racial discrimination on campus is a psychological and sociocultural stressor that can lead to the maladjustment of students within these institutions (Contrada et al., 2001). Unlike other stressors, however, experiences of discrimination are considered unique because they account for an additional stress load for minority college students that may not be experienced by non-minority students. This distress, known as "minority status stress," is postulated "to exert pathogenic effects [through] stressful experiences such as racial prejudice and discrimination that are attributable to minority group membership" (Smedley et al., 1993, p. 436-437), which may become particularly salient for AfricanAmerican students as opposed to their majority counterparts at a predominantly White college or university. Like racial discrimination occurring outside of the college context, minority status stress can "exert an indirect effect by compounding the episodic and chronic stresses faced by all students [of color] given the marginal social, political, and economic positions many minority students experience” (Smedley et al., 1993, p. 437). 
For example, in a sample of racial and ethnic minority undergraduate students, Smedley et al. (1993) found that minority status stress accounted for a significant addition to the variance in psychological distress above and beyond the contribution of students' role strain (i.e., perpetual stressors related to a student's role) and life events. Of note, African-American students had significantly higher mean minority status stress levels than the other ethnic groups on each of the sources of minority stress (i.e., social climate, interracial, racism, discrimination, within-group, and achievement). Similarly, another empirical comparison showed that African-American students at a predominantly White university campus experienced higher levels of minority stress than African American students at a historically Black university (Greer \& Chwalisz, 2007). Consequently, such high levels of minority stress experienced by African-American college students attending a predominantly White university have negatively predicted psychological adaptation in the collegiate environment (Parker \& Jones, 1999).

As it appears, the predominantly White college university context increases African-Americans vulnerability to psychological distress, which may be due in part to increased experiences of racial discrimination in these settings. Consistent with prior research, studies have documented that experiences of discrimination occurring in the college environment are linked to poor psychological outcomes (Wei, Heppner, Ku, \& Liao, 2010). These negative outcomes highlight that the campus racial climate is related to African-American college students' adjustment. While African-American students' well-being has been shown to be positively related to their feeling about the university (D’Augelli \& Hershberger, 1993), research documents that African Americans have reported significantly more racial-ethnic conflicts on campus, racial-ethnic separation, 
increased interracial tension, pressure to conform to stereotypes, and less equitable treatment by faculty, staff, and teaching assistants (Ancis, Sedlacek, \& Mohr, 2000). Subsequently, exposure to a campus climate of racial prejudice has been shown to significantly lessen African-Americans commitment to the institution. These findings indicate that racial discrimination can plague African-American students and adversely affect their college experiences on these campuses. Despite these challenges, such students have been able to matriculate through their institutions which suggest that they utilize various coping strategies to off-set the influence of perceived discrimination on their mental health.

Collectively, the theoretical models described by Clark, et al. (1999), Garcia Coll, et al. (1996), and Smedley et al. (1993) along with related empirical support provide culturally and contextually relevant frameworks for understanding the racial discrimination experiences that many African-American students encounter at predominantly White institutions. Specifically, the experiences of minority status stressors are influenced by the environmental context, including the racial composition of the college which the African-American student attends. Hence, predominantly White universities' and college environments pose a potential threat to the psychological wellbeing and adjustment of African-American students attending these schools. These students are at-risk of greater minority stress because of their encounters with increased racial discrimination which can contribute to their maladjustment to their schools. Even though a large portion of African-American students attend institutions in which they are in the racial and ethnic minority, the person-environment conflict creates minority status stress that impacts mental health. Essentially, predominantly White institutions can lead 
to a lack of fit or mismatch between the minority student and the institution if students are not aware of the psychological resources that will help them successfully navigate the emotionally stressful terrain that is inherent at these particular colleges (Cabrera, Nora, Terenzini, Pascarella, \& Hagedorn, 1999; Tinto, 1993).

\section{African-Americans' Coping with Racial Discrimination}

Despite the chronic racial discrimination and minority-status stressors that African-American students face on their college campuses, research has documented that African-Americans employ a variety of coping strategies to address such negative racerelated stress. According to the stress and coping literature, stressors are the personenvironment interactions that are perceived by individuals as taxing or exceeding their available resources (Lazarus \& Folkman, 1984). Additionally, Lazarus and Folkman (1984) indicate that a combination of one's perception of an event as stressful and their available coping responses determines whether one will have a psychological stress response. Experiencing psychological distress following one's perception of discriminatory environmental stimuli underscores the stressful nature of these experiences that occur in a given context (Clark et al., 1999). Accordingly, understanding the nature of the stress process is necessary to know how African-Americans students come to cope with the racial discriminatory stressors that they experience in their predominantly White university settings.

Coping with such stressors involves behavioral and cognitive attempts to manage, reduce, or endure the internal and external demands of stressful situations such as racial discrimination (Lazarus \& Folkman, 1984). Even among African-Americans who perceive certain environmental stimuli as a racial stressor, there are likely to be individual 
differences in the stress responses since its magnitude and duration will depend on the availability and use of coping responses. Coping responses to ethnically and racially relevant stimuli have been conceptualized as "general" or "specific" (Clark et al., 1999, p.809). General coping responses are strategies that are typically used to deal with stressful stimuli; these include anger expression, social support, and religious participation, which are particularly relevant to African-Americans. Race-related (i.e., "specific") coping refers to "cognitions and behaviors used to mitigate the negative psychological and physiological effects of perceived racial discrimination such as active coping and cognitive flexibility (Clark et al., 1999, p.809)." Clark and colleagues (1999) add that, "the efficacy of various coping strategies in reducing the chronic and acute psychological effects of ethnically relevant stimuli may depend in part, on the frequency of the perceived stressor and the environmental context in which the racial discrimination is perceived" (pp. 810-811). This means that for African-Americans students in a predominantly White college environment, their effective coping responses will be partly determined by how often they perceive discrimination in these specific contexts. Gaining an understanding of the nature and function of the coping strategies that AfricanAmerican students employ is needed for the eventual reduction of psychological symptoms experienced in such collegiate environments.

Adaptive coping responses have been postulated to minimize the psychological and somatic health symptoms that stem from racial discrimination (Clark et al., 1999). Therefore, identifying coping responses that influence the relationship between perceived racial discrimination and stress responses may ameliorate its negative health outcomes (Clark et al., 1999); however, the mechanisms by which such psychosocial coping 
strategies function as intervening factors vary and can occur in a number of ways. Psychosocial variables can lessen the harsh impact of racial discrimination by serving "as intervening factors that can eliminate or modify the source of the problem, alter the meaning of the stimulus such that it is no longer perceived as stressful, or regulate the emotional reactivity associated with the stressor" (Utsey, Giesbrecht, Hook, \& Stanard, 2008, p. 50). These psychosocial responses can be further understood within a distressdeterring model of coping (Ensel \& Lin, 1991). The distress-deterring model posits that the presence of certain psychosocial resources enhance an individual's psychological and emotional well-being, and as a result prevents the onset of stress. Together, these perspectives suggest that psychosocial resources either moderate (i.e., buffer against) or mediate (i.e., account for) the potential harmful effects of stressors such as racial discrimination.

Marginalized individuals have also developed "counterspaces" as a way to cope with racial discrimination (Case \& Hunter, 2012; Solórzano, et al., 2000). Counterspaces can be viewed as cultural resources that African-American college students attending a predominantly white institution can use to respond adaptively to racial discriminatory experiences in such a context (Grier-Reed, 2010; 2013). These counterspaces can promote psychological well-being when students gather with racially and ethnically similar students and they engage in psychotherapeutic conversations that supports that resiliency and coping in a challenging school environment (Case \& Hunter, 2012). By interacting with peers in cultural centers targeting underrepresenting groups or having informal gatherings, African-American college students at predominantly white universities have been posited to "enhance [their] well-being by challenging deficit- 
oriented societal narratives concerning marginalized individuals' identities" (Case \& Hunter, 2012 (p.257). In counterspaces, African-American students can challenge these notions by engaging in conversations about their identity, countering behaviors of the majority, and providing emotional and social support to one another in a predominantly white university (Case \& Hunter, 2012). This suggests that another important coping resource for African-American students is the formal and informal resources and gatherings targeting the communion of these students on their college campuses.

Given the individual and group level psychological processes that occur in such counterspaces detailed by Case and Hunter (2012), it is likely that African-American students attending PWI's may experience changes in their own racial identity development as a result of being in this racial context. According to Cross' Nigresence model of Black racial identity development (1971), African American's acquisition of their Black racial identity development is prompted by the racial events and stressors that they experience. Cross notes that some African-American's “Pre-encounter" status involves an unawareness of racial inequality and a lack of consciousness of oneself as Black. Hence, African-American college students attending predominantly white universities may have first-time or increased awareness of themselves as racial beings as a result of "Encounter"[ing] a series of race-related experiences that forces them to acknowledge the impact of racial discrimination in their lives. By coping with the impact of racial discrimination through their engagement in informal and formal psychotherapeutic "counterspaces" (Case \& Hunter, 2012), African-American college students at PWI's demonstrate an intentional desire and "Immersion/Emersion" of visible symbols of their racial identity and an avoidance of White cultural norms. As African- 
American students at PWI's advance through their studies over the years, it is likely that their racial identity continues to evolve and they later experience an "internalization" and security about their Black identity while simultaneously beginning to forge relationships with other racial/ethnic groups. Consistent with this theory, African-American students at PWI's would therefore achieve an "internalization-commitment" of their self-identity by achieving a balance in their own racial identity as well as the identities of others while also having a general sense of commitment to the concerns of their racial groups. Taken together, the Cross Nigresence model helps to explain how the racial identity development process can be triggered and precipitated by the racial context and climate for African-American college students attending predominantly white universities.

Moreover, research examining perceived discrimination and mental health outcomes has demonstrated that psychosocial factors influencing this relation have functioned as both moderators and mediators (Greer \& Brown, 2011; Torres, Driscoll, \& Burrow, 2010; Utsey, et al., 2008). Moderators are variables that explain for whom or under what conditions a relation between a predictor and outcome variable occurs, while mediators are variables that indirectly explain the relation between the predictor and outcome variables (Aiken \& West, 1991; Baron \& Kenny, 1986). For example, a study about racial microaggressions and psychological functioning among African-American doctoral students found that active coping, which was defined as proactive behavioral coping strategies (e.g., "I usually think ahead and organize my thoughts or ideas about future situations"), moderated the relations between racial microaggressions (i.e., perceptions of the estimation of one's personal intellectual ability), perceived stress, and depressive symptoms. Specifically, coping moderated the racial microaggression- 
perceived stress link such that individuals who perceived more racial microaggressions but were high in active coping had the lowest perceived stress scores at one year followup (Torres, et al., 2010). These findings suggest that active coping functions as a protective factor in the context of racial microaggressions that involve ascriptions of intelligence or having one's ability underestimated. Similarly, in their moderation analyses, Greer and Brown (2011) found that the influence of minority status stress on perceived stress significantly decreased at high and mean levels of disengagement coping (i.e., denial, mental disengagement, behavioral disengagement, and substance use) in a sample of African-American college students.

While there is evidence that psychosocial factors like coping can buffer against the negative effects of discrimination on mental health (i.e., moderating effect), some evidence also suggests that these factors may mediate the association between perceived discrimination and psychological distress (Cassidy, O’Connor, Howe, \& Warden, 2004). Research by Cassidy et al. (2004) found that among men in their sample of minority young adults, personal self-esteem significantly mediated the relation between perceived discrimination and both depression and anxiety. Despite the paucity of the literature, the prior studies provide some evidence for the mediating role that coping can serve in the relation between perceived discrimination and mental health functioning of African Americans. Additional research is needed to determine whether coping serves as a mediator specifically for African American college students dealing with campus-based racial discrimination.

In addition to research on general psychosocial processes of coping, there is also evidence suggesting that specific personal cultural resources can moderate and/or mediate 
the association between perceived discrimination and psychological distress. Specifically, studies provide evidence that one's racial and/or ethnic identity processes can serve as important protective factors in the face of discrimination (Branscombe, Schmitt, \& Harvey, 1999; Neblett, Shelton, \& Sellers, 2004; Sellers, Caldwell, Schmeelk-Cone, \& Zimmerman, 2003). Racial centrality has been found to serve as a protective factor in moderating the negative impact of discrimination on anxiety and depression (Sellers, et al., 2003). Experiences with daily racial hassles resulted in significantly poorer anxiety, stress, and depression for individuals with low and medium levels of racial centrality; however, there was no association between daily racial hassles and mental health for individuals with high levels of racial centrality (Neblett, Shelton, \& Sellers, 2004). On the other hand, one study by Branscombe, Schmitt, and Harvey (1999) demonstrated that attributions of past experience with discrimination and attributions to prejudice across situations had a negative effect on personal and collective well-being that was actually mediated by ethnic group identification. This model suggested that perceptions of prejudice increase identification with one's minority group, which in turn enhances psychological well-being.

As the limited research portrays, psychological and cultural resources have been documented to serve as both moderators and mediators between discrimination and health. Additional research is needed to ascertain whether these psychosocial and cultural factors function in the same manner for African-Americans in a specific environmental context such as a predominantly White university. The aforementioned stress and coping framework is useful because it incorporates racial discrimination into a larger conceptual framework that it takes into account the transaction between the person and 
environmental characteristics to explain differences in the manner in which individuals experience, cope with, and are affected by racial discrimination in a given context (Clark, et al., 1999; Lazarus \& Folkman, 1984; Smedley, et al., 1993). Hence, the present study sought to further the existing body of literature about the psychological and cultural resources such as coping, resiliency, and racial and ethnic identity by examining their links to psychological distress in African-American college students who report encounters of racial discrimination at their predominantly White university. Specifically, this research sought to close a gap in the literature by examining these coping resources as both moderators (protective factors) and mediators in the relation between discrimination and mental health in a predominantly White collegiate setting. Since a number of studies have emphasized that racial discrimination is a stressor that places African-Americans at-risk for mental illness beyond general stress, it is imperative to identify the manner in which these psychological strengths help to offset the impact of the racially-noxious stimuli that African-Americans inevitably experience within a predominantly White environment. Moreover, as the extant literature demonstrates that the first year transition at a predominantly White institution can be particularly challenging for college students of color given the racial microaggressions they may encounter, the present study focused on first year students (Solórzano, et al., 2000; Sue, et al., 2009). Given the existing research, the present study sought to answer the following research questions:

1) What is the relation between perceived campus-based racial discrimination and the mental health outcomes of depression, anxiety, and somatic symptoms among first-year African American college students? 
2) Do the psychological (i.e., coping, resiliency) and cultural resources (i.e., racial centrality, ethnic identity) moderate the relation between college racial discrimination and the mental health outcomes of depression, anxiety, and somatic symptoms among first-year African American college students?

3) Do the psychological and cultural resources mediate the relation between perceived discrimination and the mental health outcomes of depression, anxiety, and somatic symptoms among first-year African American college students?

4) Will first-year African American college students confirm the use of psychosocial strategies such as coping, resiliency, racial identity, and ethnic identity as well other coping strategies in managing discrimination and psychological distress? 


\section{CHAPTER III}

\section{Method}

\section{Participants}

The present study included a sample of first year African-American

undergraduate students at a predominantly White university in the southeastern region of the United States. One hundred one (101) students completed the survey at Time $1 ; 56 \%$ completed the post-survey at Time $2(n=57)$. Time 2 data collection was at the end of the spring semester of students' first year. The mean age of the students was $18.88(82 \%$ female). Based on student self-report, $24 \%$ identified as African, 56\% as AfricanAmerican, 6.9\% as Caribbean, and $13.9 \%$ identified as Bi/Multi-Racial/Ethnic.

There were a total of 10 students who participated in the focus groups. The first focus group was comprised of 3 females and the second focus group consisted of 7 students (2 males and 5 females). Students all identified as Black/African-American which drew them to participate in the quantitative survey and focus group; however; throughout the focus group, students disclosed their ethnic background. Across the two focus groups, students self-identified as African-American, African, Bi-/Multi-racial, and Caribbean.

\section{Setting}

Students in the study attended highly selective public university in the southeast. Enrollment for first-year African-American students at this institution is 300 and they comprise $7.2 \%$ of the undergraduate student body. The graduation rate for AfricanAmerican students is $87 \%$. The institution has an office that addresses the student development of African-American students. This office provides new student orientation, 
peer mentoring by an advanced student for first-year students, weekly study sessions with available discipline-specific tutors, a faculty-student mentorship program, an established program for peer counseling, and a parent advisory association.

\section{Procedure}

This study was designed to examine the experiences of first year AfricanAmerican college students at predominantly White institutions. Specifically, this research investigated whether students' perceptions of the racial campus climate (i.e., perception of prejudice and discrimination) was related to their mental health outcomes. Using an explanatory sequential mixed-methods (quantitative and qualitative) design (Creswell, 2014), this research sought to understand the psychological resources (i.e., coping, resiliency) and cultural resources (i.e., racial identity, ethnic identity) that students employ to alleviate depressive, anxiety, and somatic symptoms. The purpose of the qualitative data was to further explain and support the quantitative findings, so that a deeper understanding of the predicted relation between perceived racial discrimination, psycho-cultural resources, and mental health outcomes could be better understood.

Students were recruited through electronic list-serves distributed through an oncampus department servicing African-American students and were informed that their participation would be voluntary. Surveys were collected electronically at two time-

points during the school-year using SurveyMonkey. The Time 1 survey was distributed within one month of students' arrival to college, while Time 2 was at the end of the following spring semester. In addition, a small number of students $(n=10)$ participated in a brief focus group discussion to further explore their experiences with discrimination and coping. These focus groups were conducted in the middle of the spring semester of 
students' first year. Students who agreed to participate in this study and fully complete the survey were entered into a raffle to receive a gift card to the school bookstore valued at $\$ 25$.

\section{Measures}

Students completed a demographics page at the beginning of the electronic survey that included questions regarding gender, birthdate, age, ethnic background, family income level, first generation college status, and highest level of educational attainment by maternal and paternal parent/guardian (see Appendix A for a copy of all survey items).

\section{College Racial Discrimination}

Perceptions of Prejudice and Discrimination. The Perceptions of Prejudice and Discrimination (PPD) measures students' perceptions of prejudice and discrimination on their college campus. The PPD has 8-items and uses a 5-point Likert scale. Students are asked to think about their college or university and select the answer that best describes their response. Higher scores on the PPD indicate greater perceptions of prejudice and discrimination on campus. A sample item from the PPD is "I feel there is a general atmosphere of prejudice among students.” Internal consistency for the PPD was .87 across a diverse sample of undergraduate students (Cabrera \& Nora, 1994).

\section{Psychological Resources}

List of Coping Resources. The List of Coping items includes strategies such as talking with others about the problem, drawing on past experiences, or seeking support from cultural group members. In this measure, Gloria, Castellanos, and Orozco (2005)

assess the degree to which each coping strategy is utilized. Gloria et al. (2005) examined 
this construct using a 4-point Likert scale (1 strongly disagree to 4 strongly agree) and assessed the intercorrelations of coping responses. Examples of the items include "I talk with others about the problem" and "I try to reduce tension." The reliability coefficient was not assessed for Gloria et al.'s (2005) coping measure. This study determined the internal consistency of the measure to have a Cronbach's Alpha of .704 for this sample.

Brief Resiliency Scale. The Brief Resiliency Scale (BRS) assesses the ability to bounce back or recover from stress (Smith, Dalen, Wiggins, Tooley, Christopher, \& Bernard, 2008). This 6-item measure uses a 5-point Likert scale in which respondents are asked to indicate the degree to which they agree with each statement. Higher scores indicate greater ability to resist or bounce back from stress. Reliability coefficients for the BRS ranged from .80-.91 in a sample that was predominantly undergraduate students (Smith et al., 2008).

\section{Cultural Resources}

Multidimensional Inventory of Black Identity: Racial Group Centrality Subscale.

Eight items from the Multidimensional Inventory of Black Identity (MIBI; Sellers, Rowley, Chavous, Shelton, \& Smith, 1998) assess the extent to which participants believe that their race is a central part of their identity (e.g., "Being Black is an important reflection of who I am"). Responses are indicated on a 7-point scale from 1 ("strongly disagree") to 7 ("strongly agree"). This scale is appropriate for use with African American young adults and has adequate reliability (Cronbach's alpha $=.75)$.

Multigroup Ethnic Identity Measure-Revised (MEIM-R). The MEIM-R is a revised version of the original Multigroup Ethnic Identity Measure (MEIM; Phinney, 1992; Phinney \& Ong, 2007). It consists of six items designed to assess an individual's 
level of ethnic group exploration (e.g., "I have often talked to other people in order to learn more about my ethnic group"), and level of commitment, or sense of belonging, to their ethnic group (e.g., "I feel a strong attachment towards my own ethnic group"). Items are rated on a 4-point scale from "strongly disagree" to "strongly agree," with higher scores indicating a higher level of ethnic group identification. The scale has demonstrated good reliability, with Cronbach's alphas of .76 for exploration, .78 for commitment, and .81 for all 6 items.

\section{Mental Health Outcomes}

Carroll-Davidson Generalized Anxiety Disorder Screen. The Carroll-Davidson Generalized Anxiety Disorder Screen is a screening tool for generalized anxiety disorder (Carroll \& Davidson, 2000). This questionnaire is a 12-item measure that assesses anxiety symptoms including "most days I cannot stop worrying" and "I get easily annoyed or irritated." Participants are required to check "yes" or "no" next to an anxiety symptom that they have felt most days over the past 6 -months. Scores are calculated by tallying the total number of items endorsed as "yes."

Harvard Department of Psychiatry/National Depression Screening Day. The Harvard Department of Psychiatry/National Depression Screening Day (HANDS) measure is a 10-item self-report questionnaire that was developed by Baer et al. (2000) to be used as a referral tool for mental health services for people with symptoms of depression. Sample items include "been blaming yourself for things" and "been feeling no interest in things." The measure is easily scored by obtaining the frequency of occurrence of each symptom over the past 2 weeks. The HANDS uses a cut off score of 9 or higher (range 0-30) and has yielded a sensitivity of $95 \%$ regarding individuals who 
meet a DSM diagnosis for Major Depressive Disorder based on a clinical interview. This measure is also characterized by strong reliability (e.g., internal consistency $=.87$ ).

\section{Patient Health Questionnaire 15-Item Somatic Symptom Severity Scale. The} Patient Health Questionnaire 15-Item Somatic Symptom Severity Scale (PHQ-15) is a somatic symptom subscale derived from the full Patient Health Questionnaire (PHQ) (Kroenke, Spitzer, \& Williams, 2002). The PHQ-15 comprises 15 somatic symptoms, with each symptom scored from 0 ("not bothered at all") to 2 ("bothered a lot") with total scores ranging from 0 to 30 . Participants are asked to rate the severity of each symptom. The PHQ-15 is intended to function as a continuous measure of somatic symptom severity over the past 4 weeks. Items on this measure include "stomach pain" and "chest pain." The PHQ-15 score is divided into several categories (e.g. high, medium, low) to illustrate more clearly the relationship between graded increases in somatic symptom severity and various health outcomes. The PHQ-15 has already been validated in primary-care settings. The PHQ-15 has exhibited an internal consistency equal to 0.80 . The item regarding "menstrual pains" was omitted from the survey for the purpose of having questions that are applicable to both men and women in this study.

\section{Qualitative Data Methods}

Focus Group Interview Protocol. A total of 10 questions created by the researcher were used for the proposed study for the qualitative data collection (see Appendix B). These focus group questions sought to explore first year African-American students' experiences with college racial discrimination, their perceptions of its impact on their psychological and physical well-being, and the psycho-cultural strategies they employ to cope with racial discrimination. 


\section{Analyses}

The current study was correlational in nature and involved no experimental manipulation of variables. In the analyses, multiple regression was used to first examine the relation between college discrimination and mental health functioning, and then explored whether psychological resources and cultural resources served as moderators and/or mediators in the relation between racial discrimination and mental health. Specifically, moderation analyses using the Aiken \& West (1991) multiple regression technique and the mediation method according to Baron and Kenny (1986) were used. In all analyses, the mental health outcomes were from the Time 2 survey controlling for baseline mental health status at Time 1.

\section{Covariates}

Given the disproportion of men and women in the study sample and the disparate prevalence rates of mental illness for men and women (American Psychiatric Association, 2000), gender was entered in the analyses as a control variable. This procedure is consistent with prior research (Greer \& Brown, 2011; Neblett, Shelton, \& Seller, 2004). In order to control for this covariate, I entered gender into the first block of the step-wise regression in each analysis. Significant correlations between other demographic factors and the key predictors and outcomes determined additional variables that needed to be controlled for in this study. As stated above, Time 1 mental health variables were controlled for in all analyses.

Research Question 1. What is the relation between college-based racial discrimination and the mental health outcomes of depression, anxiety, and somatic symptoms for first year African-American students? 
To test Question 1, I ran linear regressions (controlling for appropriate covariates) with college racial discrimination as the predictor for each Time 2 mental health outcome.

Research Question 2. Do the psychological (i.e. coping, resiliency) and cultural resources (i.e. racial identity, ethnic identity) moderate the relation between college racial discrimination and the mental health outcomes of depression, anxiety, and somatic symptoms for first year African-American students (Figure 1)?

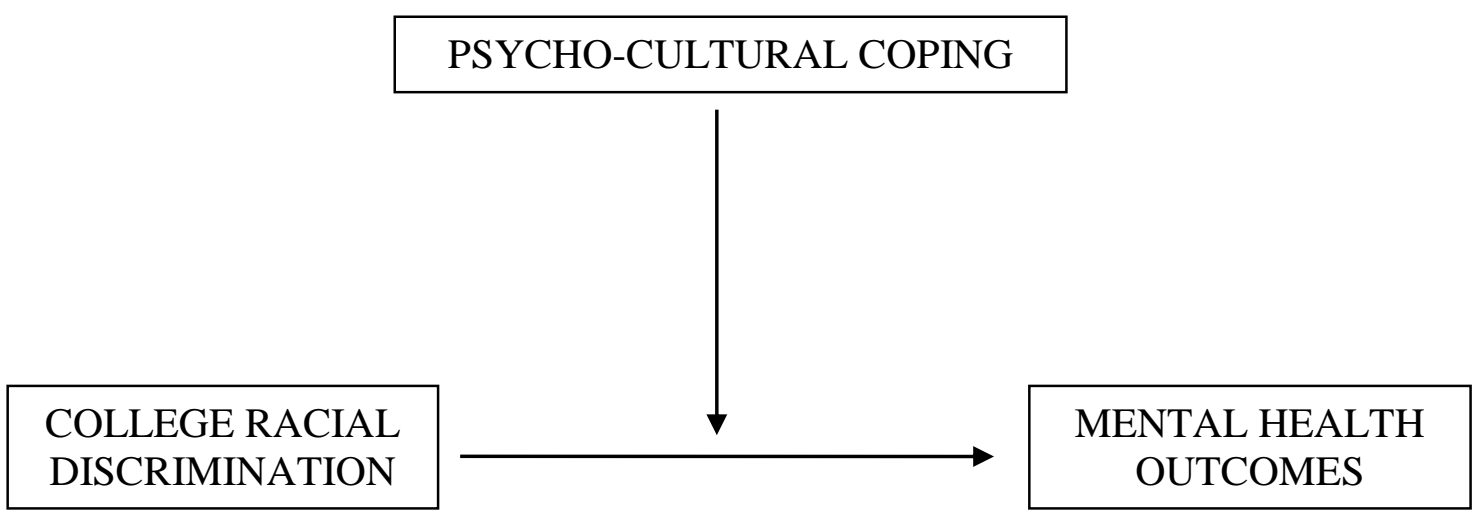

Figure 1: MODERATION MODEL

To test Research Question 2, I ran a step-wise regression using the Aiken and West (1991) method with the psychological and cultural resources for each of the mental health outcome variables. Before entering the predictor variables to the model, I first centered the variables by first determining the mean for each variable. The variables were recoded into a new variable that subtracted the corresponding mean from the original variable value. I then entered my covariate (i.e., gender) into the step-wise regression. Next, I entered the predictor variable (i.e., college racial discrimination). Afterwards, I added the psychological resource variables (i.e. coping, resiliency) and the cultural 
resource variables (i.e., racial identity, ethnic identity) in the next step. I created a product term of the predictor variable and the psychological and cultural resource variables and entered them into the regression at this step. Lastly, if the product term was statistically significant, then I would test the simple slopes to explicate the significance of this relation. Accordingly, I would calculate the "low" and "high" versions of the moderator variables by subtracting and adding one standard deviation, respectively, to the mean of the psycho-cultural factors in the sample (Aiken \& West, 1991). Based on these designated cut-points for "low" and high," the moderator variable would then be recoded into dummy codes in which the comparison group (i.e., "low" or "high") moderator variable is assigned a " 0 " and the other group assigned " 1 ". A separate interaction term (coping $\mathrm{X}$ discrimination) would be created for each group.

Two separate step-wise regressions, one for the low group and one for the high group, would be used to determine the significance of the slope for each group. The two predictors (coping variable and discrimination) would be entered first, followed by the conditional interaction term for the appropriate group. The intercept and discrimination slope would be used to graph the results at low and high levels of the particular coping variable being examined.

PSYCHO-CULTURAL COPING 
CAMPUS RACIAL DISCRIMINATION

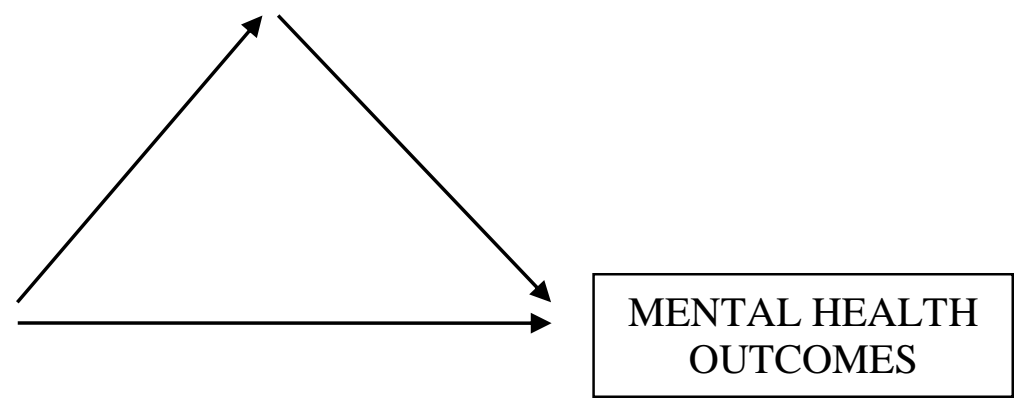

Figure 2: MEDIATION MODEL

Research Question 3. Do the psychological and cultural resources mediate the relation between perceived discrimination and the mental health outcomes of depression, anxiety, and somatic symptoms for first year African-American students (Figure 2)?

To test Research Question 3, I conducted a mediation test using the Baron and Kenny (1986) procedure which involves conducting a series of linear regressions. First, I determined whether there was a significant relation between college racial discrimination and the mental health outcomes. Next, college racial discrimination was regressed onto the psycho-cultural factors. If significant, then the third regression was performed to determine whether there was a significant relation between the psycho-cultural factors and each mental health outcomes. The covariate(s) were entered first, then the psychocultural factor variables, followed by the college racial discrimination variable. If the psychological or cultural variables fully mediated the relation between discrimination and mental health, then the regression weight for discrimination would become nonsignificant. However, if the regression weight for discrimination decreases but is still significant, a web-based Sobel test would be used to determine whether the coping factor is a partial mediator. 
Research Question 4. Will first year African American students confirm the use of psycho-cultural strategies such as coping, resiliency, racial identity, and ethnic identity as well as other coping strategies in managing discrimination and psychological distress?

To test Research Question 4, two focus groups were conducted. The first focus group was comprised of 3 female students and the second consisted of a total of 7 participants (5 female students and 2 male students). The recorded focus group was transcribed and coded using qualitative analytical techniques rooted in grounded theory (Strauss \& Corbin, 1990). Using this technique, the data were read thoroughly and major themes and sub themes were identified that reflected psycho-cultural coping strategies. For inter-rater reliability, a research assistant was given the transcript to identify the predesignated themed codes. Codes from the researcher and research assistant were compared for $80 \%$ agreement.

\section{Summary}

A sparse amount of literature exists to understand whether or not psychological and cultural coping factors operate as moderators, mediators, or both in the relationship between perceived discrimination and mental health for African-Americans. This dissertation sought to investigate the psychological and cultural resource factors that significantly influence the psychological distress outcomes in young African-Americans. The study used a regression approach supported by qualitative data to examine whether these psycho-cultural coping strategies moderate and/or mediate the association between college racial discrimination and psychological well-being in African-Americans within a predominantly White context. 


\section{CHAPTER IV}

\section{Results}

\section{Quantitative Results}

Correlations between demographic variables with predictor and outcome variables were performed and are reported in Tables 1 and 2 (p. 38-39). Racial discrimination was not significantly correlated with Time 2 mental health outcomes; however, there was a positive, significant correlation between discrimination and somatic symptoms at Time 1 .

Linear regressions with campus racial discrimination as the predictor along with significant covariates for each mental health outcome were performed. When depression was the dependent variable, the covariates were students' mother/maternal highest level of education, family income, Caribbean ethnic group, and Time 1 depression. Results showed that above and beyond control variables, racial discrimination was not significantly related to Time 2 depression. When psychological and cultural variables were added to the model, results indicated that neither coping nor resiliency were significant predictors of depressive symptoms. Likewise, there were no significant main effects of cultural resources ethnic identity and racial identity variables. Tests of interactions between discrimination and both psychological and cultural coping variables showed no significant moderating effects of any coping variable on the association between discrimination and depressive symptoms. Additionally, since there was no significant association between campus racial discrimination and depression, there was no case for testing a mediation model as this is a necessary condition to be met in mediation analysis according to the Baron and Kenny (1986) method. 
When predicting Time 2 anxiety, which included the covariate family income and Time 1 anxiety symptoms, results demonstrated that racial discrimination was not significantly related to Time 2 anxiety above and beyond controlling for covariates. When psychological and cultural variables were added to the model, results showed no main effects for any variable, and the coping constructs did not moderate the association between discrimination and anxiety. Because there was no significant association between the campus racial discrimination predictor and anxiety, there was no justification for mediation.

Lastly, when Time 2 somatic symptoms were the outcome and gender and Time 1 somatic symptoms were the covariates, campus racial discrimination was not significantly related to Time 2 somatic symptoms. As with the analyses above, there were no main effects of any psychological or cultural coping variable on somatic symptoms, and coping did not moderate the relation between discrimination and somatic symptoms. Given the lack of main effects, mediation models were not tested.

\section{Post-hoc Analysis}

The correlation matrix showed a significant association between Time 1 discrimination and somatic symptoms; thus, a post-hoc regression model was run using Time 1 constructs. The results showed that there was a significant association between campus-based discrimination and somatic symptoms at Time $1(\beta .271, t(2,83)=2.661$, $p=.009)$. There was also a concurrent main effect for resiliency with somatic symptoms $(\beta-.265, t(4,81)=-2.422, p=.018)$. Despite these significant main effects, there was no evidence of a moderating effect of resiliency on the association between Time 1 discrimination and somatic symptoms, and the mediation model was not significant. 
Table 1

Summary of Interrcorrelations of Demographic, Predictor, and Outcome Variables

\begin{tabular}{|c|c|c|c|c|c|c|c|c|c|}
\hline Measure & 1 & 2 & 3 & 4 & 5 & 6 & 7 & 8 & 9 \\
\hline 1. Gender & - & 0.069 & -0.002 & -0.164 & -0.179 & 0.07 & 0.086 & -0.073 & $.247 *$ \\
\hline 2. FamInc & 0.069 & - & $.392 *$ & $.580^{*}$ & -0.023 & -0.093 & $-.437 *$ & -0.204 & 0.102 \\
\hline 3. FirstGenEd & -0.002 & $.392 *$ & - & $.507^{*}$ & 0.019 & 0.002 & -0.182 & -0.12 & 0.007 \\
\hline 4. MomEd & -0.164 & $.580^{*}$ & $.507^{*}$ & - & 0.048 & -0.096 & $-.212^{*}$ & 0.01 & -0.06 \\
\hline 5. CaribEth & -0.179 & -0.023 & 0.019 & 0.048 & - & -0.109 & -0.107 & $.268^{*}$ & -0.02 \\
\hline 6. PrePPD & 0.07 & -0.023 & 0.002 & -0.096 & -0.109 & - & 0.131 & -0.035 & $.288 *$ \\
\hline 7. PreDEP & 0.086 & $-.437 *$ & -0.182 & $-.212 *$ & -0.107 & 0.131 & - & $.424^{*}$ & $.439 *$ \\
\hline 8. PostDEP & -0.073 & -0.204 & -0.12 & 0.01 & $.268^{*}$ & 0.131 & $.424^{*}$ & - & 0.185 \\
\hline 9. PreSOM & $.247^{*}$ & -0.102 & 0.007 & -0.06 & -0.02 & -0.035 & $.439 *$ & 0.185 & - \\
\hline 10.PostSOM & 0.179 & -0.016 & -0.121 & -0.012 & 0.014 & $.288^{*}$ & 0.253 & $.616^{*}$ & $.449 *$ \\
\hline 11. PreANX & 0.047 & $-.402 *$ & -0.15 & -0.145 & -0.077 & -0.035 & $.732 *$ & $.442 *$ & $.546^{*}$ \\
\hline 12. PostANX & 0.026 & -0.236 & -0.169 & -0.142 & 0.101 & 0.161 & $.416^{*}$ & $.761 *$ & $.305^{*}$ \\
\hline 13. PreCOPE & -0.134 & 0.179 & 0.032 & 0.042 & -0.06 & -0.075 & -0.417 & -0.136 & -0.012 \\
\hline 14. PreRES & 0.035 & $.364 *$ & 0.157 & 0.152 & 0.067 & 0.192 & $-.618^{*}$ & $-.347^{*}$ & $-.210 *$ \\
\hline 15. PreMIBICen & 0.018 & -0.042 & $-.230^{*}$ & -0.079 & -0.236 & -0.117 & -0.127 & -0.162 & 0.153 \\
\hline 16. PreMIBIPub & 0.031 & 0.106 & -0.084 & 0.068 & 0.03 & 0.183 & $-.223^{*}$ & -0.18 & $-.230 *$ \\
\hline 17. PreMIBIPriv & 0.094 & 0.029 & -0.156 & 0.004 & -0.194 & -0.071 & $-.284^{*}$ & -0.199 & -0.102 \\
\hline 18. PreMEIMExp & -0.109 & 0.008 & -0.11 & -0.05 & -0.009 & 0.099 & -0.2 & -0.14 & -0.004 \\
\hline 19. PreMEIMComm & -0.039 & 0.008 & -0.136 & 0.009 & -0.075 & 0.123 & $-.239 *$ & -0.161 & 0.164 \\
\hline
\end{tabular}


Table 2

Summary of Interrcorrelations of Demographic, Predictor, and Outcome Variables

\begin{tabular}{|c|c|c|c|c|c|c|c|c|c|c|}
\hline Measure & 10 & 11 & 12 & 13 & 14 & 15 & 16 & 17 & 18 & 19 \\
\hline 1. Gender & 0.179 & 0.047 & 0.026 & -0.134 & $.035^{*}$ & 0.018 & 0.031 & 0.094 & -0.109 & -0.039 \\
\hline 2. FamInc & -0.016 & $-.402 *$ & -0.236 & 0.179 & $.364^{*}$ & -0.042 & 0.106 & 0.029 & 0.008 & 0.008 \\
\hline 3. FirstGenEd & -0.121 & -0.15 & -0.169 & 0.032 & 0.157 & $-.230^{*}$ & -0.084 & -0.156 & -0.11 & -0.136 \\
\hline 4. MomEd & -0.012 & -0.145 & -0.142 & 0.042 & 0.152 & -0.079 & 0.068 & 0.004 & -0.05 & -0.009 \\
\hline 5. CaribEth & 0.014 & -0.077 & 0.101 & -0.06 & 0.067 & $-.236^{*}$ & 0.03 & -0.194 & -0.009 & -0.075 \\
\hline 6. PrePPD & -0.035 & 0.162 & -0.075 & 0.192 & -0.117 & 0.183 & -0.071 & 0.099 & 0.136 & 0.123 \\
\hline 7. PreDEP & 0.253 & $.732 *$ & $-.416^{*}$ & $-.417 *$ & $.618^{*}$ & -0.127 & $-.223^{*}$ & $-.284 *$ & -0.2 & $-.239 *$ \\
\hline 8. PostDEP & $.616^{*}$ & $.442^{*}$ & $.761^{*}$ & -0.136 & -0.347 & -0.162 & -0.18 & -0.199 & -0.14 & -0.161 \\
\hline 9. PreSOM & $.449^{*}$ & $.546^{*}$ & $.305^{*}$ & -0.012 & $-.210^{*}$ & 0.153 & $-.230^{*}$ & -0.102 & -0.004 & 0.164 \\
\hline 10. PostSOM & - & $.404^{*}$ & $.667 *$ & -0.079 & -0.181 & 0.09 & -0.112 & -0.007 & -0.088 & 0.084 \\
\hline 11. PreANX & $.404 *$ & - & $.617 *$ & $-.277 *$ & $-.490 *$ & -0.071 & -0.188 & $-.303^{*}$ & -0.203 & $-.220 *$ \\
\hline 12. PostANX & $.667^{*}$ & $.617^{*}$ & - & -0.261 & $-.477 *$ & -0.087 & -0.243 & -0.176 & -0.164 & -0.181 \\
\hline 13. PreCOPE & -0.079 & -0.277 & -0.261 & - & $.421^{*}$ & $.415^{*}$ & $.271^{*}$ & $.393^{*}$ & $.306^{*}$ & $.423^{*}$ \\
\hline 14. PreRES & -0.181 & $-.490^{*}$ & $-.477 *$ & $.421^{*}$ & $\ldots$ & 0.072 & $.218^{*}$ & $.275^{*}$ & 0.16 & $.280^{*}$ \\
\hline 15. PreMIBICen & 0.09 & -0.071 & $-.087 *$ & $.415^{*}$ & 0.072 & - & -0.019 & $.520 *$ & $.463^{*}$ & $.726^{*}$ \\
\hline 16. PreMIBIPub & -0.112 & -0.188 & -0.243 & $.271^{*}$ & $.218^{*}$ & -0.019 & - & $.350^{*}$ & $.249^{*}$ & 0.057 \\
\hline 17.PreMIBIPriv & -0.007 & $-.303 *$ & -0.176 & $.393^{*}$ & $.275^{*}$ & $.520 *$ & $.350^{*}$ & - & $.416^{*}$ & $.509^{*}$ \\
\hline 18.PreMEIMExp & -0.088 & -0.203 & -0.164 & $.306^{*}$ & 0.16 & $.463^{*}$ & $.249^{*}$ & $.416^{*}$ & $\ldots$ & $.683^{*}$ \\
\hline 19. PreMEIMComm & 0.084 & $-.220 *$ & -0.181 & $.423 *$ & $.280 *$ & $.726^{*}$ & 0.057 & $.509^{*}$ & $.683 *$ & \\
\hline
\end{tabular}




\section{Qualitative Results}

Focus groups further examined first year African-American students' experiences regarding their adjustment to college Students noted having academic, social, and racerelated stressors on campus. They reported employing various academic resources, social-emotional, and psycho-cultural strategies to manage their overall college stress. Academic Stressors

Students noted their academic stress and how it negatively affected their psychosocial functioning and physical health, which included having various negative emotional reactions and physical symptoms related to their academic demands and college adjustment. They admitted to experiencing feelings related to anxiety (including worry, apprehension, nervousness, hypervigilance), depression, inadequacy, confusion, jealousy, anger, and disappointment. Some students attributed their feelings of disadvantage to fewer educational opportunities available in their hometown:

“...Seeing that I came into the E[ngineering] school, you feel disadvantaged that your school didn't provide what you were going into. So [one particular high school] was specifically designed for engineers. Mine was specifically designed for marine biologists. You know, I didn't grow up in [that area] and I didn't get those opportunities. You know, you feel down about it but you still feel thankful for what you were given. And I was given something but I just chose to do something else. Nothing I can do about it but you know you still feel like, "Oh, I should've done that, you know. I definitely notice that I get angry a little bit more because I'm in the E[ngineering] school, as well. Like, it's more of, like a 
jealousy thing because, like you said, in high school, you're, like a number: you're competing with somebody else for a spot. And in E[ngineering] school, everybody's kind of in the same boat, but like, others have that advantage because it's like, they're from a different part of [the state]. Like in my school...not everybody had the opportunity to have like, the higher level math or anything. So, I've noticed that it's a lot more stressful...It's more of like, my high school was like, like you got the standard stuff. Like, they didn't prepare you for...college...I feel like I am not prepared for what they're, like, giving me."

Likewise, one student commented on how her concerns about grades lead to worry about her future career goal fulfillment: "I...stress a lot about my future and, like, if I get a bad grade in this test then it's gonna ruin my GPA, and I'm not gonna go to law school. And it'll, like stress me out about my future." Another student described her disappointment in her unmet academic expectations due to academic rigor: "I think worry and stress is true and also disappointment because, like, you know, I guess, we're all smart and used to getting good grades so it's a lot harder to get the good grades you want. So just, like, I guess disappointment in not getting the grades that you expect or you thought you would get sometimes." Additionally, another student described how her feelings of a lack of preparation for college likely contributed to the academic anxiety and perfectionism she experienced in college:

"I mean even today, I talked to my memoir teacher and she was saying how, like, my paper was good, but it was like, she wanted me to go to the next level. She was like, "This would be good for high school but this is not acceptable in college." And it's like you never get trained to think to that deeper level or 
analyze, to go above whatever the high school level [is]. Like, it's almost something you have to teach yourself...And I even tried explaining to her, like, it's hard for me to go to the next level when I'm barely understanding what's the basic message getting put across. And so I feel like I get that feeling of being unprepared. And I have a big anxiety or apprehension towards writing and I don't know if it's that pressure to be so perfect or that because... you have to write to meet what your teacher likes. You can’t write for yourself, I guess. So I get anxious about that."

Students also identified experiencing the physical effects of their academic stress and college adjustment. These somatic responses included sleep deprivation, frequent illnesses which led to class absences, and lack of available time to exercise due to academic demands.

\section{Academic Coping}

Utilizing academic supports on campus was a common form of academic coping. Students noted taking advantage of academic services such as studying in the library: "I'll go to the library a lot. I'm there just about every day so that's one of the things that helps me out." Additionally, students sought support from university personnel and peers by "talking to a dean... or talking to an older student." One student also found office hours to be helpful as she received "a few resources... with extra information" from her professor. Some took comfort in knowing that they "hav[e]... a support system for everything" at their university and thus, valued that they have access to more academic resources than in high school:

"There are resources...in high school but not necessarily a vast amount of 
resources that I have here. So, it's just knowing that if something doesn't work out, I have somewhere to turn to [and] fall on. Like I have that guarantee that I may not have had in previous years. So I think I am in a better mental and physical health."

Some students also indicated that they used specific departmental academic resources catering to African-American first years students. One such program was a peer advising program which pairs first year African-American students with non-freshman African-American students for mentorship. There was also a weekly study time designated for African-American students with optional tutoring services.

\section{Mental Strategies}

A number of constructive psychological strategies, such as positive self-talk and reframing negative thoughts, were used to alleviate academic stress. Some students normalized their stress by reminding themselves that "everybody thinks [the university] is hard...I'm not different or anything." For example, participants also noted that avoiding comparing themselves to others helped to lessen their stress: "I try not to compare myself to the other people in the school because everybody's different and everybody, has like, their strengths and like, weaknesses so I just kinda like do the best of my personal ability.” Similarly, one first-year African-American student stated, “...I know there's specific areas that I know that, like, a " $\mathrm{B}$ " is just the highest grade that I'll get in that. And like, personally math is just not a strong point so getting a "B" on a test that everyone's complaining that a "B" is horrible, I'm happy." I'm okay, so I know, like my levels of, like, where I should be amongst, like different subjects. So I guess that helps...like, my attitude towards grades and the sort." 
Recognizing when additional help is needed was another psychological process that some first year African-American students used to manage their college-related stress:

"I've really learned this year that, not to be too prideful to ask for help, to admit that I don't know something...I mean I still struggle with it now, asking for help. I really don't like asking for help. Not that I feel like I can do it by myself, but that I feel like everyone else has problems, too, and they don't really have time for mine. But I learned that it's important to ask for help and admit that I don't know everything."

Some African-American first-year students maintained a more balanced perspective of college beyond academic achievement:

"I try to remind myself not to get caught up in the numbers. I feel like in high school, we were trained to have the highest number in everything in order to get into a good college or go to the next level after high school. And here, focusing so much on numbers, you miss the greater opportunities here, like the culture and the diversity, and the different activities you can do outside of the academic piece. And so I just try to remind myself that it's not all about numbers. Just to do my best ability."

“...There's so much more besides, like academic stuff going on so I try not to focus... $100 \%$ of my time on academic activity. So I think just being well-rounded also counts, so that's how I try not to stress out with academics." 
One first-year African-American student found focusing more on her academic effort and less on her grades to prevent academic-related distress: "Like I guess I try not to focus on, like, the grade that I might get because, like, usually when I do that then, like, that's when I...get stressed. So, I try to...just focus on the effort I put into doing my homework." In order to maintain a positive mood, some students also found that using optimism, humor, and being open-minded helped them to manage their stress.

\section{Individual Study Strategies}

Beyond institutional supports, students noted using various study strategies which have proven effective for them and have helped in managing their stress levels. Participants reported making lists, organizing their schedule, prioritizing tasks by deadlines and difficulty in order to manage their academic demands. For example, one student said, “...I take it one day at a time. I try to do the hardest thing on my list first and gradually it gets easier..." Another student mentioned, "Setting realistic goals. Like knowing that...I should have studied more or so or knowing that a " $\mathrm{B}+$ " is what I'm gonna get and just be happy with what, you know, realistically what you can do yourself." For one student, this kind of approach was mentioned specifically in the context of academic stress:

“...I try to prioritize because if I have too many things on my plate then I'm gonna have to get rid of some things because if I kind of try to do everything, then I'm not gonna do my best on all of the things. And I mean, I've been stressed since I came to [this university] more than I've ever been stressed in my entire life before. So I mean yeah, I see there's this huge pressure to compete with the rest of 
the student body so I, like, try to prioritize and kind of put things first if they need to be."

\section{Social Support}

Outside of academic supports and effective study habits, participants reported using social supports to manage the stressors of college. Participants also found "working with peers" to be helpful. Specifically, one student indicated, "I usually find somebody who's as stressed as I am and work together because usually it's divide-and-conquer. So, you know, we can't really do each other's work but we work on it, you know. We help each other and that alleviates a lot of stress." Similarly, another student reported, "I try to seek help from, like other people, whether it's like...working with classmates or talking to, like an older student. I find that they have more of a sense of what to do than us first years so that helps.

Talking with peers, friends, parents, and significant others were found to facilitate adjustment to college. For example, receiving parental, familial and romantic partner support was also noted as ways in which multiple first-year African-American students managed the stressors of college. One young woman noted the importance of talking to relieve her stress: “...My way to deal with things, I guess with me being a female is talking. So, I mean I don't say my problems to everybody. I have certain people that I talk to but I make sure I get it out so I'm not bottling up negative thoughts."

\section{Physical Activity and Self-Care}

Furthermore, self-care strategies were also used by first year African-American students to manage their stress on campus. Students identified leisure activities, exercising, and playing sports as ways to ease stress. These activities were reflected in 
statements like, "I think my health overall, it has probably improved since I've been here because when we first got here, they really stressed, like the mental and physical health as far as eating right and sleeping and exercising. And I've tried to incorporate more of those things into my daily routine that I didn't do previously." And, "I'm one of those people that just puts on headphones, goes to the gym, or I'll take a walk, or go play a sport."

Religion and Spirituality

Religious and spiritual practices were also used to cope with the stressors of college. A few students commented that prayer, in addition to their involvement in Christian student organizations, helped to mitigate their stress levels. One student cautiously stated, "I don't mean to offend anybody but I'm religious so I honestly pray." Another student described her involvement in religious clubs on campus: "Yeah, I'm in [two Christian student groups]. And everyone's like really open and part of it is that beyond that we're all students, we also have this common, like, religious, like, goal and so I think that also brings us together as Christians rather than white Christians or black Christians. So in a way, yeah, I feel so at home with them."

\section{Social Stressors and Coping}

First-year African-American students had mixed experiences regarding their interactions and relationships with peers at their university. One student noted that the social aspect of college was more challenging than the academics: "Well for me personally, like school was hard but socially was the hardest thing about coming to college more than academics..." Two students commented that their experiences in the college residences were less than favorable: 
“...a lot of kids I know had great experiences in their dorms and everything but mine wasn't necessarily great. Like, our dorm isn't necessarily, like that friendly so I was kind of, like, surprised at that...At least for my hall, it's always quiet and like, it's just coming to school was more lonely than what I expected, which is harder than doing the work."

One student who self-identified as being "mixed" with "Black and White" races reported that she felt "a lot of pressure" regarding the social aspect of college because one is "almost forced into the racial group that [they're] defined as or...appear[ed] to be": "And not that you don't have the ability to branch out and be friends and interact with people of other races or different colors or however you wanna look at it. But I feel like in the black community there's such a strong push to be the black community. If you're black you need to go to [the department that provides services for the African-American students] and you need to...do this with this black organization, you need to do that with that black organization. And it's, like, [big sigh] I don't know. I don't feel like I'm not accepted or welcome to other organization but I feel like there's such this big push to embrace your blackness. And not that that's negative but it's like, there's so many other races and cultures and ethnicities here that I mean I don't really know how to explain it. I don't wanna make it seem like it's bad to want to strengthen your community. But I feel like it almost sends across a message that you should be a part of our community only and focus all your time or most of your time with us because we want our community to be stronger or more close-knit...if you go to a different 
group you almost stand out. Like, you stick out like a sore thumb and it's uncomfortable. So it almost doesn't make you wanna reach out and learn new things because you don't feel as welcomed or you don't feel included."

Furthermore, one first year African-American student believed that socioeconomic class played a role in the formation of friendships at college despite being from the same region of the state as the majority of the students from the university.

Geographical region was also noted as a factor that affected one's ability to make meaningful connections at college. One student from the west coast of the United States noted that she struggled socially with making connections with peers at the university. She explained:

"I don't know. I think also part of it is the fact that I'm out of state, so I don't know, like, a lot of what people do here. Just like-like, a lot of things about me are already different. Like, I notice the way a lot of people dress and stuff is really similar, and so,... where I'm from a lot of people dress different... I mean, a lot of times I feel weird but, like, I don't know. It's kind of hard to explain because, I feel, like, kinda out of touch with a lot of things people do here. So, I mean, I feel like that's a lot of times-I don't know. Like, I don't know where to fit in a lot of times. I took summer classes here last summer, and a lot of the friends I have now are the friends I made last summer. And it had nothing to do with, like, race or anything. We had, like, a lot of the same situations and stuff, and so, like, and a lot of them were out of state, too. And so I felt, like, a better connection with them because they also didn't know, like, a lot of the stuff that people, like, do here, so." 
High school education experiences were also mentioned as factor in the social adjustment to college. One student described having a different social experience than her peers because she had attended a college preparatory boarding school and had the experience of meeting and living with people of diverse backgrounds, and developing close relationships with peers in a college residential hall: “...I went to boarding school so I've had this. This isn't the first time I've had this new living experience. Like, I had my experience with mingling with dorm-mates when I was 15 , so I feel like starting that young and understanding...how it is meeting people and finding ways to, like, join groups, and like join people or figure out who you will or will not be friends with was easier for me because I had already been through it." She also noted, "I'll go out, like, to white frats on Friday and, like, house parties with black friends on Saturday, and I have, like, no problem splitting up my time amongst two." Furthermore, many of the first-year African-American students concurred that they could make significant social connections by expanding their social network beyond individuals in their dormitory. For example, a student stated “...I was expecting to become somewhat friends with my suitemates but I realized that you kind of have to...join organizations, put yourself out there, and meet other people and you can't necessarily rely on your hall-mates or suite-mates."

In sum, first-year African-American university students reported experiencing stressors that were academic and social in nature. While these stressors often had a negative impact on students psychologically, they found effective ways to manage their difficult emotions related to the rigorous academic demands at their university and finding their social niche. They positively coped with academic and social demands by 
using university resources, effective study habits, social support, exercise and self-care, and religion and spirituality.

\section{Race-Related Stressors}

\section{Awareness of Being a Racial Minority}

Beyond academic and social stressors, many of the first-year African-American students noted having an increased awareness of their racial minority status. One student stated, "I'm from [a town], which is by no means [is] ... all black or anything like that. It's definitely majority white but I never realized that I was [a] minority really until I came to [this university], which is really different. I wasn't expecting that at all. Another student expressed,

“...I was in [a high] school [that] had a class of thirty that I went [to], like, for four years, And so there were, I think, three blacks in the...class of thirty. And like, I mean, I recognized that I was one of the three blacks but it was never made, like, apparent. And then, like, I come here, and it's just, like, there's only twothere's like, three black girls on my hall and...And it's just like, wherever you go... I just recognized more that I'm, like, standing out almost like a black dot in a sea of white, which before, like it didn't bother me. I didn't care, like, being different: it was fine. But it's just...made more noticeable [here]."

Similarly, another student commented, "Yeah, I do, like, completely agree. That was, like, my experience, too, like, growing up. I grew up in the same town all my life. I knew everyone, and everyone knew each other, and I knew who my friends were, and we were all cool with each other. And, like, being black wasn't, like, a big deal. Like, I knew I was the only black person but, like, who cares? And, like, I came here and I just became, 
like, more aware of, like, that I'm a minority. Especially, like, going out to, like, parties and whatever. Like, I would know-I would be, like, the only black person here and, like—it's like, kind of a shock to, like, realize that you're, like, a racial minority."

One student found that he was "rediscovering [his] Blackness" in college. He noted that in high school there appeared to be a dichotomy in which one could not be both smart and African-American, so therefore, most of his friends were white in high school, and in college he developed many friendships with African-Americans: "I didn't start making black friends until I actually came here. I've made more black friends here than I have, I guess, my whole life..."

On the other hand, one student reported that despite growing up in a predominantly white town in the North, she did not experience an increased awareness of her racial minority status as a first year African-American student: "I just, like, I don't know. It doesn't, like, feel any different than I felt my whole life. I mean my town is generally white...I think the first time I actually had black friends besides, like, family friends that I would, like, go to school with, was by, like, 7th, 8th grade. And then—but I already had all of my white friends from before so it was just kind of an addition. But then in high school it was also the same way. But I guess, I don't know. I'm from the north so it's a little different."

Furthermore, a female student expressed feeling conflicted between having to choose between racial groups and was learning to identify herself as bi-racial. She stated, “...I do feel like I try my best not to identify with one race, because I am mixed. And, like, my family is not only one race so I can't think that... So I try to remember to acknowledge that - I don't know how to explain it. Just to embrace 
who I am and not accept one or the other just because [African-Americans] accept me more than the other one. And it's difficult and it pushes me out of my comfort zone a lot...And I really was made aware of that this year coming to [college].

Like, I have a friend, a fourth year, and he's so great, but he's mixed, too, black and white...He told me when people say, “Oh, you're black" or whatever, he's like, "No, I'm biracial.” And that really hit home to me. I feel like I need to do that more often because I'm not one or the other, even though I may be conceived as that."

\section{Racial Campus Climate}

When asked about the campus racial climate, some first year African-American students expressed a broad range of perspectives. One student described the campus as friendly despite being racially self-segregated: "I think, like, in regards to race, people are generally, open and, like, friendly, like, people of different races. But at the same time there's definitely a tendency for races to remain in their respective race group." The campus was described as a racially tense environment by a number of participants. For example, the university campus was described by one student as "racially charged" and also "racially self-segregated" by another student. Others echoed a similar sentiment in which they emphasized that the university had a "white elitist culture" in which many peers were "pompous" and that "[the university] just seemed, like more uptight... and stiff-necked". Students also noted that despite the university being located in the south, it did not have a feel of "southern hospitality" which they presumed was related to many of the students being from the northern part of the state where the culture is less typical of 
southern warmth and culture. One male student described the university as having a "sophisticated ignorance" in which individuals were smart but still ignorant.

Another reflected on the racial self-segregated campus climate both considering the behaviors of minority and majority student perspectives that may led to the tense racial campus culture: "I feel like you have to look at it both ways. Like, non-whites may exclude African Americans, but I feel like African Americans definitely exclude whites from their activities, too, which I think adds to, like, I won't say hostility but I guess, like, in the, like, biggest way to say hostility between the two groups. Because it's like both sides aren't, like, making an effort to, like, mesh together, which will obviously, like, make issues among people." One student disagreed about the majority of the campus climate being "racist" and asserted that "people are afraid to go against the status quo. Like, it's the white frats; you're not gonna go against that. Like, [it's] status quo so because of that things are slow to change because no one wants to change them, not because people are racist just because they're comfortable with the way it is. That's what my perception is..." Moreover, some first year African-American students found that the racially segregated campus led them to have stronger connections with African-American students. One student attributed the self-segregation to the lack of inclusiveness by other racial groups on campus towards blacks and reasoned that African-American students are forced to connect with fellow African-American peers who have been "polite" and friendly:

"But one thing that I guess I've noticed about the white kids and the Asians in Physics and in Calc[ulus],...they're not always accepting to you. They're not always as forth-coming... If you try to, I guess, reach out that hand and try to be, I 
guess, sociable and stuff, they don't always respond to you...And I feel like that's one of the conditions that you have to keep in mind when talking about those things. I mean, some black students, they feel a big need to get involved in those black communities because other white people won't accept them."

One student in particular noticed that the "Black community is very close-knit" and asserted that he did not "associate with any [one] race" because he was multi-racial and was raised to be open and friendly to people of all races. Yet, some students felt pressured into the African-American community as a social group because of the frequent university outreach and programming that was organized specifically for this racial student group. One female student who came from a racially diverse family background in a rural part of the state felt there was an emphasis from the university to be involved in African-American groups and university activities:

"So when I went to elementary school, like, my whole school was all white and, like, the black people there, we all said hi because we're all related, we'll see each other on Sundays, every holiday, it's no big deal. But, like, it's kinda weird to come here and see it because it's, like, "Okay, we want you to, like, come to the [African-American professional groups, University departments] And it's like, 'Okay, this is different.' Because, like, you don't have, like, an out. Like, when I was younger, like, black just didn't mean anything because, like, we're all from, like, a farm, so it's, like, everybody just got along with everybody. And, like, here they make a big thing out of it. Like, "You're black, come to this... I guess they want us to be together but, like, me and my cousins and stuff-my cousins are, like, the same way. But me and my cousins are all, like, mixed." 
Moreover, some students felt that there was an assumption that Black students'

preference for same race peers. For example, students noted, "I think they already

perceive me as...just another black person who's...going to end up being friends with

other black people. Like, you're not trying to like, build relationships with them. It's just hi and bye."

\section{Perceptions of African-Americans' Treatment on Campus}

First year African-American students described a range of perspectives regarding their perceptions of how they were treated on campus. Academically, students felt supported by faculty and perceived that they were treated fairly: "As far as faculty, academic-wise I've been treated perfect, like I'm no sort of anything different at all. I think it's been fine... academic-wise I think it's totally, like, equal.” Another student agreed that the institution "does a really good job of reaching out to African American students and giving them opportunities and stuff." In relation to peer interactions, the same student expressed that: “Its friendly interaction but I don't think a lot of students would go out of their race to become friends with someone of a different race at times." There was also an acknowledgement of interpersonal situations with peers that have been "uncomfortable". For example, one student expressed feeling that her white peers were afraid of her despite her attempts in showing friendliness towards them:

“And, like, people I've talked to, like—you know, first week of school everybody's to be all friendly, say hi to everybody, things like that. And I'd say hello and we'd smile and, like, really the only people who would respond back to me in, like, a welcoming way would be black students, which I wasn't expecting. Because I talked to some white guys and they'd be, like- like they were scared of 
me and I was like, I don't know what I'm-I'm just saying hello, like, you know, we're all new here, stuff like that. So I wasn't really expecting that so I kind of-I mean different. Like, back at home I have all kinds of friends: black, white, Asian, Spanish. Like, here most of my friends are black so I wasn't expecting that and it was kind of, like, you know, a different experience. But I'm trying still to branch out. I don't hold that against - it was just different than what I was used to."

\section{Perceptions of Mistreatment of African-Americans}

Regarding their perceptions of mistreatment towards African-American students, the first year students admitted to having racial discriminatory experiences. Students also described that they had experienced mistreatment because of their race by out-group members: "There's definitely kids here who are, like, completely, racist or they act strangely [to African-American students]." For example, one male student expressed that "there's a lot of, you know, look-out-the-corner-of-your-eye condescension" at the university. He "described his peers as "inadvertently condescend[ing] him through their non-verbal and verbal interactions and discussions about course work:

"Some of the guys, you know, they give you the dirty looks, you know, a little sly off to the side, or, you know, I-know-better-than-you type mentality. You know, there's some people that's like, “Oh, have you studied for Digital Logic?” “Oh, I don't need to study for that one. You know, that's just an easy class."...And then we come to a supplementary class where everybody needs help. They were the two people sitting in front and I was like, "Okay, okay, I see how it is." "You didn’t wanna help me... Oh, I thought you didn't need to study?...I get a higher 
grade on the test because I-I had to work harder for that but it's just—some things, it's just, you know, racism isn't blatant...it's hidden.”

Similarly, another male student commented that there are preconceived notions about his academic ability. Specifically, he noted that his intelligence has been discounted on numerous occasions: “I remember one guy wouldn't take my input for the longest time. My input was right but he would not take my input at all."

One student felt that the university's "racially charged" environment may have been related to a racial incident she experienced in her dormitory even though she realized that "there's no way...to prove" that the ill-treatment was race-related. She described an incident in which she complimented dorm-mates who were outside of her racial group on the nice aroma from cookies they were baking and felt that they might have thought she wanted to steal their baked goods due to their guarded facial expressions and lack of response.

A male first-year student who identified as West African described numerous experiences in which he was ignored by known peers outside of his racial and cultural group which was different from his communal cultural background. He stated, 'It's just that straight tunnel vision, and you're just like,... We had a conversation and now you're, like, doing a tunnel vision thing"... They do the tunnel vision thing, and I've noticed it's so much of them. It's straight tunnel vision...I guess it's how they were raised, their area, their socioeconomic [status]...And it's, like, it's multiple; it's a lot of them. It's not just this one person or just these two people. It's, like, their own, like, social custom...you're choosing to continue to walk and not acknowledge my presence as a human being." 
Similarly, another male student believed that the "tunnel vision" phenomena that was identified by the other male in the focus group may be related to lessons individuals learned about comporting themselves in public. He purported:

“Maybe it's just people aren't aware. You know, I grew up where you're always constantly aware of your surroundings. My father always taught me, because with his experience, you're always constantly aware of your surroundings. You lookyou know, you're constantly analyzing your environment...A lot of people are complacent...I'm always the one, you know, who grew up where there's shootings in the trailer park. You know, there's gun threats at school. You constantly—even in the hallway you're looking around, seeing if somebody's gonna fight you. I mean, my school wasn’t horrible but, you know, you grew up with that, I don't wanna say jail mentality but you're looking around." The African-American men discussed a number of racial encounters in which they felt that individuals outside of their racial group may have felt threatened or intimidated by them. One student felt that an older white woman in a parking lot staircase was intimidated by him because of his race as she turned back due to her claims that she had forgotten to lock her car. One male student prefaced his experience by highlighting the racist history of the university: "Well, I mean, one thing you consider about this area is the cultural context of it. [This university] was one of the most racist universities...It was just awful, the things that they did...At one point they would pay black students full tuition if they did not come ... or apply [here]..." He later described an experience in which he believed that he was perceived as a physical threat to a man in passing: "I walked by a car at, like, 8pm, holding my physics textbook, coming back from office 
hours, and then I hear, like - alright so this one random white guy walks by the car. Okay, nothing. I walk by: he locks the door twice. I'm like, "What? I'm the one with the physics textbook. I'm not gonna assault you with it..." Both men also stated that they were checked prior to entering a football game for what they believed was for no other reason than race. In one case, the first year male student indicated that he was dressed in a suit and tie exactly like his Caucasian friends and later reported the racial discriminatory incident to the dean of students. The other male student described an incident in which a male seemed to be afraid of him as he turned around and began walking backwards to watch him after they passed one another near a campus library: "What am I gonna do in flip flops with a Darth Vader shirt that says, 'Come to the dark side. We have cookies.' I am not a threat to you. Why are you specifically turned around? It's almost like I was an instant threat to him. I didn't see any reason specifically why I was a threat to him. You could've passed by any other white person possibly but you probably wouldn't have turned around. And it's like, you couldn't turn your back on me, like I was just gonna, you know, jump out with swords or stuff like that, try to hurt you...Like, I was automatically gonna come at you."

Students also noted experiences in which non-African-American peers responded to them stereotypically. For example, one male first year African-American student highlighted that many people assume that all of the African-American men on campus are student-athletes on scholarships. A female student noticed that people of other races communicate to her using what appeared to be African-American vernacular. Similarly, one male student stated that individuals made assumptions that he was not African- 
American but instead Latino and would approach him by speaking Spanish. Another male also discussed meeting his roommate for the first time and recognizing the assumption that men who were not African-American will not give him standard handshake to as his roommate attempted to give him a hand shake that he presumably may have seen African-American men give one another in the past.

In contrast, one student reported having never experienced racism or discrimination and wondered whether she was "just oblivious at times" or whether her petite frame made her appear to be less threatening. Nevertheless, she stated feeling "disconnected" and did not feel welcomed by other students regardless of their racial backgrounds...Another female student reported that she did not have a "racial encounter where [she] felt...put down or excluded or people had to take extra caution or extra measures because of the color of [her] skin" and felt that African-American men tend to have such experiences: Black males are really struggling, especially here,...it's a surprise for a black male to be here in the E[nginering] school and do well...And I feel like that's also a problem in society, or an issue in society. But I do feel like [after] hearing their stories - that it's more-racism is more of an issue for males."

Moreover, a few female students commented on having racial discriminatory experiences by individuals within their race. One student specifically felt racially insulted by accusations of "acting white" from African-American college peers because of the differences in their speech and mannerisms: “...you talk white,...you act white.” She also noted that other African-American peers made assumptions that she engaged in stereotypical behaviors and activities such as using slang and smoking marijuana. Similarly, another female student from out of state who reportedly struggled with feeling 
accepted by peers, reported feeling annoyed when other African-American students would comment that her interests were scorned and likened to that of Caucasians, "That's only what white people do". A bi-racial female student in the group also noted that she received comments from peers such as "Oh, you're trying to act white," or "You're trying to dress white," or "You're trying to dress black". She believed that social class was related to how people perceived her because she felt that "more white people have the money to buy those preppy name brand clothes that make you look like you're dressing white."

\section{Psychological Impact of Racial Discrimination and Coping}

These students reported feeling a number of negative emotions as a result of the racial discrimination they experienced on campus. They stated feeling "annoyed," "thinking the [person's behavior] was strange," and "hurtful." These negative racial incidents added to the loneliness that one person felt in the dormitory. One student male student described feeling "confused" and "baffled". Coping strategies such as humor and "laugh[ing] it off", "go[ing] along with it, or "mak[ing] a joke back," and "just try[ing] to get over it" helped students in managing their race-related stressors. In addition, after going through such experiences of racial discrimination, one student learned the nuances of racial discrimination and noted the way in which he copes: "I've come to discern there's racism like I-don't-like-you and then there's racism I'm-scared-of-your-peoplebecause-I-have-this-misconceived-notion. And I think it's because that fear, that breeds ignorance. And I think you can't be mad at people for being dumber-well, not dumber than you. Just raised...less worldly." He also coped by reflecting on the improvement of racism over the past decades: 
"Yeah, and it's a whole lot better than it was, like, 30, 40 years ago, so [verbal emphasis] much better. So, I mean, I'm still thankful for that, you know. Other people went through, like, a lot of difficult times just so I could come here...but compared to their experience, you know, they went through hell. And it's like, I just feel it wouldn't even be right to compare that experience to them getting, like, beat up and stuff, you know? So I guess I just try to put things in perspective that way."

He also considered the type of environment in which one was raised as a way to cope with racial discrimination: "I mean, you can't be - at the end of the day you can't be upset at them because they didn't get the diverse upbringing, or because they didn't meet someone who's in AP Physics and black at the same time, or things like that. I mean, at the end of the day, you just can't let it get to you." Additionally, one female student expressed that her experiences with racial discrimination has made her more "openminded" about connecting with individuals across racial groups.

Students also focused on their academic goals and "not let[ting] it serve as a distraction" as a way to cope with racial distress: "I'm just gonna come here for what I came here for. Get my degree and then be done with it"; "for me it's reminding myself why I'm here...I'm here to get that degree... when I'm done here I'll have my degree from [this university] which is a name that carries, you know...I'm here for that paper and that's all that matters in the end." Similarly, many students recognized that their experiences of racial discrimination positively affected them psychologically by becoming motivation for their academic success: "Use it as a drive... socially it's not what I expected or wanted but because of that, I'm just gonna do even better at school.” 
One student also found comfort in reminding herself that her bachelor's degree will be the same as her white peers, and thus, focused on the overlapping similarities in the pursuit of higher education despite noting the differences in the struggle or process of educational attainment. Receiving social support from open-minded White peers was another coping method that was found to be helpful regarding racially tense or uncomfortable situations. Campus involvement was also stated to be an important "I try not to focus on it. I just try to be, like, outgoing and stay involved in things, like joining organizations and, like, just being involved so I'm not reminded of the situation."

One first year female student indicated that she used her religion and involvement in Christian student groups on campus to cope with t racial discrimination despite recognizing the differences in socio-economic status amongst them:

“...Everyone's like really open and part of it is that beyond that we're all students, we also have this common, like, religious goal, and so I think that also brings us together as Christians rather than white Christians or black Christians. So in a way, yeah, I feel so at home with them. Even within that group, yeah, of course, sometimes I feel like slightly disconnected because of, like, different experiences based on class background. But that has really helped me to cope is basically my religion."

Another student denied experiencing blatant campus discrimination, yet found her spirituality to be important in how she coped with less obvious forms of racial discrimination: “I don’t think I have experienced overt racial discrimination. But the way I do cope with the ones I feel are covert is basically mostly religion and my upbringing." 
Although first year African-American students denied using campus resources to cope with racial discrimination, one student mentioned that (African-American) deans at the office that caters to African American students often brought up issues related to the race and campus discrimination. University African-American deans encouraged first year students to use discriminatory experiences "as an opportunity to learn more about yourself". Thus, this student expressed that she "learned more about African-American culture at the university than in high school or anywhere else."

A few students noted that the psychological impact of having experiences with racial discrimination led to questions about which community they belong on campus: “... I think that it, like, all ties into, like, me trying to find my place here. Like, as far as, like, where I fit, like, racially and just, like, culture-wise and everything. Like, I think it ties into that in, like, how I'm still, very unsure." Similarly, another student indicated that she is "still trying to figure our [her] niche racially..."

\section{Parent Racial Messages}

Many students also coped with racial discrimination by thinking about specific things about their race, racial or ethnic origin, and family values. A number of first year African-American students reported that they received messages from their families about coping with racial discrimination. One male student stated that his parents always said, "The racism that's hidden is ones that are usually the worst, because you can't see what's happening. You can't react to what's happening." Another male student expressed that his family taught him to "prove somebody wrong" if they had preconceived notions of African-Americans or Latinos so as not to be defined by one specific group. His parents instilled that he first see the humanity in individuals and not their race: "You 
should see me as a human being and not define me to some - not to define me to the Latinos, not to define me to the, you know, blacks, because I'm not gonna do that to you, you know. I'm gonna walk up to you, cherish you as a human being and your personality." He also noted coming from a high school in which the majority of students came from low socio-economic backgrounds and interacted with one another regardless of race. On the other hand, the other male student stated that while his West African parents did not necessarily raise him with specific lessons about being in a predominantly white educational setting, watching their struggle to succeed in the United States taught him strength and perseverance.

Students identified specific family lessons related racial discrimination and educational achievement and success. One student reported that hearing her father's experience with racial discrimination and the lessons he learned taught her to "ignore that kind of stuff and...work hard and achieve a lot in your life." She was subsequently informed that "people will disregard your race and they'll merit you on, like, what you accomplish." She was taught the value of her hard work and told not to miss the opportunity she has in college. Also related to education, one student learned from her parents emphasized that "racial minorities achieving is one of the best ways to like end discrimination." One student's parents reportedly shared their racial discrimination at a similarly large in-state public institution, and learned lessons such as "just know who you are, know where you come from, don't let someone else's decision change the way you do things."

Some students received specific messages about racial discrimination and interracial relations. One student who grew up in the rural south noted that her parents 
transmitted racial messages that were "black and white" which she did not understand in her childhood and adolescence; however, the relevance of these parent racial messages became clearer during the first year of college. Another student reported that her parents experienced much racial discrimination throughout their youth and had much resentment towards Caucasians which she felt was projected onto her: that she felt they also wanted her to have: "I feel like my dad feels like I should have that resentment towards white people, as well, even though I don't. And when I don't, it seems like he gets really upset with me. Like, I'm like kissing up to them or whatever." In contrast, one person indicated that race was not emphasized in her family: “...For me my parents are, like...the topic of, like, race doesn't really, like, come up with us, like, at all or anything. We're just people. Like, we look at everyone as people...So I think it has to do also with, like, family upbringing..." Her parents were described as "not black and white" but instead thinking "gray" and raising her to do the same. Moreover, one student learned that "you can't say anything to hurt me more than somebody else can that's in my family", which taught her to let racial incidents "bounce back" and not to affect her negatively: "It's like, you may be able to say something and try to hurt me, but it's like, you're only making yourself look worse and showing your true colors.

In summary, the qualitative data highlights two primary areas of stressors for first year African-American students. Students detailed their academic stressors and the impact of such stressors on them both psychologically and physically. They developed effective strategies to manage their academic demands and to maintain their physical well-being. While, students felt that they were treated fairly by academic personnel, they reported none to few experiences with racial discrimination on campus and varied with 
how they perceived the campus racial climate. The differences in their perceptions of the university environment and how they coped with race-related stressors can have lots of meaning and interpretation and therefore, lends itself to further discussion. 


\section{CHAPTER V}

\section{Discussion}

The purpose of this study was to investigate the association between perceived racial discrimination and mental health in a specific environmental context. This relationship was examined amongst first-year African-American students attending a predominantly white university. Although there may be personal advantages of attending a predominantly white institution (e.g., cross-cultural learning and social interactions), campus racial discrimination can result in significant psychological burden for AfricanAmerican college students. Since racial discrimination has been linked to a number of negative health and psychological outcomes (Clark, Anderson, Clark, \& Williams, 1999), this study sought to understand the psycho-cultural factors that may mitigate the physical and psychosocial consequences of race-related stress of first-year African-American students. Qualitative data were projected to help explicate the details related to the predicted quantitative associations between racial discrimination, psycho-cultural factors, and mental health outcomes. While the proposed quantitative findings did not demonstrate a relationship between perceived campus discrimination at the start of the semester and mental health outcomes several months later, post-hoc analyses showed a significant concurrent relationship between campus racial discrimination and somatic symptoms for Time 1 data only. Moreover, there was no evidence that psycho-cultural coping factors changed or explained the nature of the association between perceived discrimination and mental/physical health. However, the qualitative data highlighted the 
ways in which first-year African-American students identified academic, social, and racerelated stress and coping at their university and became the primary focus of this dissertation research. The shift in the methodological approach of this research from quantitative to qualitative allowed the qualitative results to provide meaningful explanations for the null quantitative findings.

The initial quantitative findings for this study yielded no significance for the relation between perceptions of campus discrimination and mental health and physical outcomes (i.e., depression, anxiety, and somatic symptoms). Additionally, there was no evidence that psychological or cultural coping factors explained, moderated, or mediated the association between discrimination and mental health. However, post-hoc analyses indicated that there was a relation between racial discrimination and somatic symptoms for the baseline (Time 1) data. Specifically, students who reported higher levels of perceived discrimination also reported higher levels of somatic symptoms like stomach pain, back pain, headaches. Although psycho-cultural factors did not moderate or mediate this relation, there was a concurrent main effect for the resilience variable, with higher levels of resilience predicting lower levels of somatic symptoms. These results are consistent with past research that shows a main effect and specifically an inverse association between coping and mental health (Matthews et al., 2013).

In the qualitative analyses, first year African-American students' college distress reported that they experienced negative psychological and physical effects related to their college stressors and used effective strategies to mitigate such stress. These emotional sequelae included feelings related to anxiety, depression, inadequacy, confusion, jealousy, anger, disappointment, under-preparation, and feeling disadvantaged. They also 
reported having decreased sleep, frequent illnesses which led to class absences, and limited time for exercise due to academic demands. Specific to their academic stressors, students identified utilizing campus resources (i.e. office hours, library, peer study groups, cultural departments targeting African-American students). They also employed various individual study and organizational strategies in order to manage their academic demands such as writing lists, scheduling, prioritizing tasks according to difficulty level and deadlines, and realistic goal setting. In addition, students used their own internal psychological resources to manage their college-related distress as self-awareness of the need of additional help and reframing negative thoughts. Also, a number of students found having a focus on their academic effort rather than their grades to be helpful in minimizing their school stress. Some students also held a balanced view of college which included both academic attainment and valuing other benefits of college such as taking advantage of opportunities beyond the classroom. Receiving social support from family, friends, and romantic partners and using self-care strategies including obtaining adequate sleep, participation in leisure activities, exercising, and playing sports were used by firstyear African-American students to manage their stress on campus.

Taken together, these findings of general college stressors of first-year AfricanAmerican students are consistent with the construct of students' role strain (Smedley et al., 1993) and coping responses (Ensel \& Lin, 1991; Lazarus \& Folkman, 1984). According to the qualitative data, it appeared that students' primary stressors were academic in nature and hence, related to their role as a student. As a result, they reportedly employed adaptive coping skills to mitigate or deter depressive, anxiety, and somatic distress from furthering increasing. Students appeared to use planful problem- 
solving and prosocial coping strategies to effectively manage their general college stressors and denied using any negative coping methods or engaging in excessive behaviors (i.e., alcohol, drugs, smoking, sex) to manage their distress. These qualitative results suggest the possibility that students' effective strategies may serve to moderate the relation between their college stressors and mental health such that increased intrapersonal strategies including coping and resiliency, in addition to academic resources, may be related to lower levels of depression, anxiety, and somatic symptoms (Utsey, et al., 2008).

An analysis of the qualitative data regarding race-related stressors and racial discrimination first requires a recognition of the diversity within the Black diaspora that comprises this sample. The variability in first-year African-American students' responses regarding campus climate, race-related stressors, and coping with such distress appeared to have intersections with gender, geographic region of origin, socioeconomic status, bi/multi-racial backgrounds. The below findings suggests that it is important to understand how intersectionality plays a critical role in African-American students adjustment to college in terms of their perceptions of the campus climate and experiences of racial discrimination (Cole, 2009; Williams \& Nichols, 2012).

In regards to the campus racial climate, participants had varying perceptions of their university atmosphere. Some first-year African-American students described the campus environment as friendly and open-minded. Despite these positive experiences, these students recognized the tendency for the student body to be self-segregated. Some students also described the institution as being a "white elitist culture," "conservative," "racist," and having a "sophisticated ignorance". The student body was described as 
homogenous which consisted of the majority of students from the same region of the state, socioeconomic status, and similar likes and interests. While not all predominantly white institutions in the literature have been given such descriptors, it is likely that these descriptions of the campus climate are specific to this highly selective state university which tends to draw majority students from the aforementioned demographics. Yet, the "racist" description of the campus has been reflected by other African-American students in existing qualitative research on their perceptions of campus climate and experiences with racial microaggressions (Solórzano, et al., 2000).

First-year African-American students' perceptions of how they were treated on campus depended on the specific domain. A number of students made distinctions between treatment from professors versus their college peers. Students also noted that they were treated fairly by professors and academic staff; however, many reported having difficult connecting with peers. This finding is in contrast to existing literature in which African-American students have reported ill-treatment by professors that was perceived to be race-related (Solórzano, et al, 2000). Importantly, the intersection of regional and cultural differences, along with the upper-middle class socio-economic status that comprised most of the student body, was likely a factor in how participants were treated as African-American peers within this university context. Students from other regions of the country, lower to middle socioeconomic statuses, and bi-racial backgrounds specifically noted that such factors affected their psychological adjustment to college. For example students who were raised in racially diverse small towns where people had a similarly lower socioeconomic status were surprised to encounter the racial selfsegregation on campus and had difficulty making significant connections with non- 
African-American peers. The majority of participants found the African-American community to be very "close knit" and welcoming towards them as opposed to other racial peers. Additionally, the type of schooling experiences one had prior to college seemed to play a role in students' perception of how they were treated on campus and likely related to their adjustment to college. One female student, who attended a private boarding college preparatory high school, stated that she was accustomed to making friends outside of her race. Thus, although there was agreement across some respondents, the variations in responses about the campus racial climate and perceptions of treatment towards African-American students depend on a number of demographic factors and schooling experiences unique to each individual. Existing research on this topic has not discussed the variability in perceptions of campus racial climate and perceptions of treatment of African-American students. Instead, research has posited that such experiences do not vary and are similar across students (Ancis, et al., 2000; Cabrera \& Nora, 1994; Solórzano, et al., 2000). The present research highlights that the perceptions of campus climate are not generalizable within a racial group. Hence, understanding the perceptions of the campus racial climate of African-American students attending predominantly white universities will require a closer examination of the intersecting identities and factors that are unique to each the individuals within the sample (Carter, 2006; O’Connor, 1999; Williams \& Nichols, 2012).

There were also distinct gender differences in racial discrimination in the form of racial microaggressions on campus. The men in the focus group reported multiple experiences being perceived that they were viewed as a physical threat and their intellectual capacity was often undermined or challenged by peers. They also noted a 
number of incidents in which they experienced passive mistreatment by peers such as being ignored when seeing them in the campus community. This gender distinction in racial discrimination experienced by African-American men has been documented in the extant literature (Chao, Mallinckrodt, \& Wei, 2012; Smith, Allen, \& Danley, 2007; Solórzano et al., 2000). However, contrary to the literature, are reports of racial discrimination experienced by within-group members: women indicated a number of situations in which they were accused of "acting white" by other African-American peers based on their speech, interests, style of dress, and lack of participation in stereotypical activities (i.e., smoking marijuana). These experiences of within-race discrimination, coupled with the lack of openness they experienced from Caucasian peers, reportedly affected where students fit in racially on campus. Unlike past research, the present study highlights that African-American students' perceptions of racial discrimination on a predominantly white campus occur by both out-group and within-group racial members. This finding suggests that both inter-group and intra-group racial discrimination can affect the psychological adjustment of African-American first year students.

Students identified various psychological and emotional effects of the racial discrimination they experienced at their university as first-year African-American students.

The majority of students reported experiencing negative emotions (i.e., hurt, annoyed, baffled, confused) related to their experiences of racial discrimination consistent with the literature (Solórzano et al., 2000). On the other hand, for two female students, both of whom were raised to embrace all races and cultures, they found positive psychological effects of their experiences of racial discrimination. These students appeared to be raised 
to be "color-blind" in which race was not emphasized and instead valuing the humanity in all races (Coleman, Chapman, \& Wang, 2013). One student highlighted the benefits of being at a predominantly white institution (PWI) was that it was an opportunity to step outside of her cultural comfort zone. For another student, it was an opportunity for crossracial learning and inter-racial dialogues since she had Caucasian friends with whom she would talk about racial discrimination. Thus, such race-related conversations appeared to be therapeutic as they offered empathy and validation for student's lived experiences as an African-American on the university campus and at-large (Eller \& Abrams, 2004; Schofield, Hausmann, Ye, \& Woods, 2010). On the other hand, for many students who were not raised "color-blind," they indicated that they positively coped with discrimination by allowing it to serve as a motivator for their academic achievement. Racial discrimination became an internal drive to for academic success rather than allowing it to be a distraction away from their overall purpose for being in college - to attain their Bachelor's degree (Sanders, 1997).

First-year African-American students received a number of parent messages throughout their upbringing that helped them cope with racial discrimination. These parent messages about race can be thought of as racial socialization in which parents instill specific information to their children about race and living and coping as an African-American (Hughes et al., 2006; Stevenson, 1995). Many participants reported that they learned specific ways about coping with racial discrimination. One student admitted that she had not fully understood the relevance of her parents' racial socialization messages regarding coping with discrimination until she began college. Being in her particular university environment may have likely made the issues of race 
and racial discrimination more salient given how she and the majority of participants perceived the campus racial climate. For some participants, they were racially socialized at a young age through family oral histories and intergenerational messages of overcoming life's challenges. Henceforth, it is possible that these parent racial messages have influenced first-year students' experience at a predominantly white institution by serving as motivators for their academic achievement and likely instilling resilience for managing racial discrimination from peers. Participants' identification of childhood and adolescent racial socialization messages may have positively influenced their adjustment to college by receiving validating, encouraging, and empowering messages to not only succeed but also using these racial/cultural lessons as coping mechanisms for the negative effects of racial discrimination. Research by Brown and Tylka (2011) supports these results as their study of African-American college students attending a PWI demonstrated that racial socialization moderated the relation between racial discrimination and resilience such that racial discrimination was negatively related to resilience for students who reported fewer racial socialization messages and was no longer associated with resilience for those who reported a greater number of these messages. Thus, the present study suggests that such psycho-cultural processes likely increase the resiliency of African-American first-year students encountering racial discrimination in a predominantly white university context.

Some participants noted that their families shared narratives about their views of race and racism. It appeared that parents' acculturation level was related to the racial socialization messages that participants received from their parents. For one student whose parents migrated from the Caribbean to the United States as young adults, she 
perceived that her parents did not harbor any negative feelings towards Caucasians. They raised her not to think in "black and white" but rather in the "gray," which likely led to her having what appeared to be a "colorblind" worldview. She was often reminded by her parents that they was no difference between her and her peers and was encouraged to befriend them. Similarly, a male participant who was originally from West Africa, noted that his parents did not talk about racism and had doubted that they had encountered racism. He stated that they did not transmit racial socialization messages and instead emphasized having a hard work ethic. Given the differing socio-political history between individuals from the Caribbean and Africans and African-Americans from the United States (Tormala \& Deaux, 2006), it is possible that parents' acculturation shaped the type of racial socialization messages transmitted to their children: "Black immigrant parents' experiences in racial majority countries and their tendency to minimize their minority status [in the United States] may have implications for the types of racial socialization messages they give their children (Joseph \& Hunter, 2011, p. 346). Relatedly, since Black immigrants often make fewer attributions of racial discrimination than Blacks who do not have a recent immigrant history (Deaux, et al., 2007), it is therefore, a possibility that the migration, acculturation experiences, and racial/ethnic identity of students' parents influenced the racial socialization messages or the lack thereof regarding coping with racial discrimination at their predominantly white institution.

Differences in the perception of the campus culture and adjustment to college appeared to be shaped by first-year students' own racial identity and the racial socialization messages they received throughout their upbringing from parents and close relatives. Students who were raised with colorblind messages in which the notion of 
equality across races was emphasized in the home and negative African-American racial experiences were not discussed in the home appeared to perceive the campus environment as more welcoming and less racially charged. While on the other hand, students who received early messages about racial injustices amongst African-Americans including their parents' and family members' in addition to their own acculturation level were likely more aware of the racial tension on campus and more easily recognized when someone was committing racial microaggressions. It is likely that for such students who were racially socialized to have a racial lens through which they view themselves and were taught how to effectively cope with inevitable racial discrimination may have had increased knowledge of their minority status and the stressors related to it. This minority status stress as coined by Smedley et al., (1993) may be more salient for students who were reared to have a keen awareness of race, racial discrimination, and thus, may be more perceptively sensitive to a racially tense campus climate.

African-American first-year students' racial identity and racial socialization seemed to be partially related to how they coped with campus discrimination. For students who were raised to be colorblind, they saw themselves as more equal to their majority peers and were likely to have a more racially diverse peer group. They saw their non-African-American friends as part of their social support system and used their interracial friendships as an opportunity for cross-racial dialogues and informal learning. Students who received early family narratives about their racial experiences used the lessons learned as a motivation for their academic achievement, although many reported feeling disconnected socially. It appears that coping with racial discrimination was typically linked to students' academic achievement. Concordant with the literature, a 
qualitative study found that positive racial socialization messages have been linked to high-achieving African-American adolescents such that they saw their academic success as an opportunity to counter negative societal stereotypes about African-Americans' intellectual capabilities (Sanders, 1997).

These findings are consistent with many students' predominant stressor academic success - that that was identified throughout the focus groups. As first year university students transitioning to college, it is reasonable to expect that students' most pressing demand is succeeding academically. It is then understandable that students identified more academic stressors than they did racial discrimination. Since people may have a finite capacity for addressing stressors in their lives, first year African-American college students may have to make deliberate choices about how to allocate their psychological resources in the context of a campus perceived by some as racially tense and divided. Given that the academic rigor of college is new and challenging, these demands require that first-year African-American students devote their internal resources to more salient stressors such as coping academically since their academic success may be a huge part of their self-esteem (Awad, 2007). Hence, it is possible that students may be less attuned to the less overt forms of racial discrimination like racial microaggressions during their first semester of college. Rather, students are possibly attending to the academic burdens and hassles of being a new college student and less so racial stressors. Even students who did identified encountering racial discrimination or struggling with the racially tense campus climate used such experiences to encourage and motivate them academically. These results highlight the salience of such AfricanAmerican first-year students' primary identity as a student. Hence, the likely need for 
them to develop adaptive coping strategies even in the face of adversity such as racial discrimination, to manage "students' role strain" — perpetual stressors related to their role as students (Smedley, et al., 1993). Regardless of the source of the stress, whether it was academic or race related, most students coping strategies were focused on helping them become more successful academically in such an academically rigorous and reportedly racially challenging environment. It is probable that students channeled their coping strategies to their sole purpose and goal of being in college to perform well academically and graduate from their university. There was some overlap in the strategies used for coping for both academic and racial stressors such as social support from family, friends, romantic partners, and also religion and spirituality. Psycho-cultural factors such as racial socialization messages were enacted in the face of race-related stress and not academic distress. However, psychological coping and resilience appeared to be employed across both contexts of academic and racial distress. Many students spoke to their motivation to succeed and not allowing such stressors to discourage them from their academic and professional goals.

Many of the students seemed to have been in a "Pre-encounter" or "Encounter stage of racial identity development prior to college which shifted to the "Encounter" or "Immersion" stages of racial identity development after being in a particular predominantly white university context (Cross, 1971). It is possible that the specific context of the participant's university in conjunction with the students past racial discrimination experiences, racial socialization messages, the intersection of their socioeconomic status and gender, have contributed to making first-year African-American students' race more salient to them and increased their understanding of their 
marginalized racial status on campus. As a result of attending a reportedly racially divided campus with targeted resources for African-American students, students likely experienced an increase in their racial identity as they noted being more aware of themselves as an African-American. Some came from small towns in which individuals had similar lower to middle class socio-economic statuses, different regions of the country, and experienced a strong sense of community with their peers regardless of race. Another noticed that despite coming from the region of the state as many of the majority students and having many Caucasian friends prior to college, the differences in socioeconomic status between many of the African-American students and Caucasian students at the university made him more aware of his race. As a result of these various factors, many first-year African-American students reportedly felt an increased sense of connection to the African-American community at their university. On the contrary, some students noted shifts in their racial identity while still struggling to determine with whom they felt most comfortable on campus.

In addition to the unique environment of the predominantly white university that may attribute to the increase in racial identity of many of the participants, their racial identity growth can likely be understood by further examining the developmental context of being first-year African-American students. As emerging adults navigating their roles, relationships, and independence, these students have multiple identities that are developing simultaneously and in which they are trying to negotiate within a given context (Arnett, 2000; Erikson, 1968). One student reported that she did not understand the racial socialization messages that her parents shared with her about racial discrimination throughout high school until coming to college. Other students 
commented on the lessons learned about racial discrimination from their parents regardless of noting when those messages became salient for them. Although they did not state at what point they truly absorbed the racial socialization messages from their families, other students stated the many messages about coping with racial discrimination such as using it as a motivator to attain academic success and "proving others wrong" in their assumptions about them. Yet, it is a possibility that the first-year African-American students' racial identity is developed with maturity and in the context of an environment that made them more aware of themselves as African-Americans and their lived experiences as African-Americans (Syed \& Azmitia, 2008, 2009, 2010). Specifically, the university climate which was described by many as "racially tense," "self-segregated," "racist," and "unfriendly" may have led to increased understanding of their family's race messages which may have led to increased racial identity and thus, ultimately increased coping and resilience for first-year African-American students in such an environment.

This developmental process underscores how time and maturation plays may play a critical role in first-year African-Americans students' race-related social-emotional development. Beyond racial identity development, these qualitative findings suggests that awareness of racial discrimination is likely also related to length of time spent on campus and how that intersects with one's development over time in a specific context. The majority of participants in the study reported having new encounters with racial discrimination in the form of racial microaggressions and the experiences identified appeared to differ by gender. Many of the participants had not experienced racial discrimination prior to beginning college and a few denied experiencing racial discrimination at the university and others reported having racial discriminatory 
experiences with both Caucasian and fellow African-American students. Being in their particular university context likely made them become aware of racial discrimination for the first time. A late adolescents' and young adults' university can be conceived of as the socio-environment in which their ethnic-racial identity further develops as they also experience social demands and transitions as first-year African-American college students (Umaña-Taylor, et al., 2014). Therefore, in this context, college students are immersed in a setting in which they are encountering new racial experiences including racial discrimination and making meaning of those experiences against their familyupbringing and racial socialization messages.

These results help to explain the low sample mean for the discrimination measure (Perceptions of Prejudice and Discrimination) which corresponded to "strongly disagree to disagree" in regards to having such experiences on campus. Perhaps with time as students successfully matriculate through their university, their capacity to perceive racial discrimination would increase. Likewise, since research indicates that perceptions of racial discriminations are not limited to single incidents in the moment but also extends to historical experiences from one's past and those vicariously experienced through others, then it is possible that as African-American students successfully matriculate through a racially intense and self-segregated university, they will accumulate more experiences of racial discrimination of themselves and through others (Utsey \& Ponterotto, 1996).

\section{Methodological Strengths and Weaknesses}

In the quantitative analyses, the small overall sample size and the high attrition rate likely resulted in a lack of statistical power needed to detect significance. The particularly low sample size for the second time point may be due to attrition due to the 
end of the semester time period in which students often feel overwhelmed with final academic responsibilities. As a result, students may have been less committed to completing the follow-up survey amidst their coursework deadlines and final examinations. Hence, a larger sample may be necessary to have results consistent with the theory and research on racial discrimination, coping, and mental health processes.

It is also a possibility that the measures used in the quantitative analyses might have had face validity but were lacking in content validity. The scales used may not have adequately measured the constructs that they were intended to examine in this study. In regards to the racial discrimination measure, the majority of participants indicated that they "strongly disagree" to "disagree" with most items on the campus discrimination measure, and there was little variability across respondents. In addition, the lack of association between racial discrimination and mental health may be explained by the slightly more than half (i.e. five) of the eight items on the measure being related to perceived discrimination perpetrated by faculty/administrators; during focus groups, students' reportedly felt they were treated fairly by academic staff and denied experiencing racial discrimination from them. Based on the qualitative data, Students' racial stressors were related to racial microaggressions committed by non-academic staff and peers. Students' reported interpretation of racial discrimination experiences and the negative perceptions of the campus racial climate were related to their social experiences and inter-group racial contact which was captured by only three out of the eight items on the campus racial discrimination measure. In regards to the coping and resiliency measures, these items may not have fully captured the type of strategies students used to manage their psychological distress despite seeming to be both face and content valid and 
consistent with the qualitative data. Therefore, such measurement limitations highlight the importance of mixed-methods as qualitative data may better capture AfricanAmerican students' experiences with discrimination that quantitative study is unable to elucidate.

The mental health measures used in this study also may have had some limitations for this particular sample. Specifically, the depression and anxiety measures used were based on the diagnostic criteria for clinical depression and anxiety which may not be the most sensitive measure in detecting such symptoms in a non-clinical sample since these measures were likely originally normed on a clinical population. Additionally, the group means for each of the mental health symptoms were also relatively low in comparison to the possible total scores for those measures which might suggest that students are not experiencing significant levels of depressive or anxiety symptoms during their first-year of college. These low means of depression and anxiety symptoms also match the low base rates for depression and anxiety in the general population. College students with higher or clinically significant levels of depression and anxiety were likely not available to participate in the study or may have withdrawn from school for psychiatric reasons. Furthermore, the low rates of anxiety and depression may have been buffered or moderated by the psycho-cultural factors (i.e., coping, resiliency, ethnic/racial identity, racial socialization messages) that students discussed in the focus groups.

Although the overall means for the somatic symptoms measure were also relatively low when compared to the total score possible, post-hoc analyses showed that there was a direct positive association between racial discrimination and somatic symptoms at baseline. It is possible that students experience race-related stress in college 
somatically as opposed to depressive and anxiety symptoms. Of note, the somatic symptoms measure had the greatest number of items on the measure in contrast to the mental health measures which may have provided a greater range of symptoms from which to select, thus, allowing it to more sensitively detect variations in somatic symptoms. Also, given that students were in a new academically challenging environment that poses great demands on them physically, students may experience distress somatically as result of their long study hours. The unique demographic group of this highly selective institution consists of the majority of students who are in the top few percent of their high school class. These students may be more vulnerable to high somatic stress levels and burnout which often manifests somatically in such a high pressured and intense academic environment. In addition, students' awareness of their somatic stress may overshadow their depression and anxiety as they might readily notice their physical stress and minimize their psychological distress. Similarly, both the depression and anxiety measures include items related to physical symptoms, so it could be that the somatic measure better examines their distress.

Moreover, participants may have held negative attributions or stigma about acknowledging their depression and anxiety symptoms which could have led them to under-report such symptoms or respond in a socially desirable way. On the other hand, it could be that students were unable to label their emotional stress because of the multiple stressors they were experiencing as first-year students and could have likely been more attuned to the physical manifestations of stress in their bodies.

The lack of significance in the moderation and mediation analysis for ethnic and racial identity in the relation between racial discrimination and mental health may be 
related to the developmental context of first-year African-American students. According to the quantitative descriptive analyses, the mean scores for the ethnic and identity measures indicate that participants' ethnic and identity may still be developing. Specifically, the means for ethnic identity commitment and exploration was slightly past the "neutral" range. Similarly, for racial identity, the mean score for the sample corresponded to the "neutral" range for racial centrality and between the "somewhat disagree" to "neutral" range for public regard. Although the group mean for "racial private regard" corresponded to the "agree" range, the former findings could suggest that students' overall sense of themselves ethnically and racially is still evolving. The qualitative data suggest that these first-year students were having "encounter" and "immersion" experiences regarding their ethnic/racial identity (Cross, 1971). Moreover, the students who participated in the focus groups may have been a unique subset of the sample who were beginning to explore and make meaning of who they are ethnically and racially in the context of a supportive environment with racially similar peers. The focus group experience may be viewed as a historical event that may have served as a flight into their ethnic/identity development and later influencing those participants' response on the post-assessment. Hence, the quantitative results might likely be different if the sample were advanced undergraduates such as third or fourth-year African-American students who have spent more time had increased encounters and immersions in this specific university context and would have likely experienced more racial discrimination throughout their undergraduate tenure.

The qualitative results of this study may provide a more nuanced and idiosyncratic examination of academic and race-related stressors of first year African- 
American students attending a predominantly white university. Although there were only a total of two focus groups and an underrepresentation of men in them, which limits the external validity of the findings regarding our understanding of racial discrimination and mental experiences of first year African-American students attending predominantly white institutions, the richness of the qualitative data highlight the diversity amongst African-American students and the intersectional factors unique to these students on a whole and individually.

Moreover, the findings from this study underscore the importance of an explanatory sequential mixed methods research design (Creswell, 2014). The qualitative data helped to extrapolate the null quantitative findings. Its internal validity helped to provide an analysis of the unique attributes about this particular predominantly white institution that may further explain the insignificant quantitative findings. Since this university has numerous targeted academic and psychosocial resources for AfricanAmerican students and a history of the highest graduation rate for African-American undergraduates, these specific characteristics of this sample may have further contributed to the null quantitative findings. The extent literature and theories related to the associations between perceived discrimination and mental health functioning of AfricanAmerican college students have not examined the contextual resources that serve as buffering coping factors in mitigating psychological distress in this unique setting. Thus, the quantitative and qualitative results from this study may have limited generalizability to other predominantly white institutions. 


\section{Implications and Conclusions}

This research has a number of implications for predominantly white universities. The institutions should consider the perception of the campus racial climate and be intentional in creating an environment that addresses academic success holistically by promoting psychological and physical well-being. As part of this supportive setting, appropriately addressing racial microaggressions experienced by African-American firstyear students will be necessary to mitigate the ill-effects of such racial discrimination. On-going multi-cultural programming is needed to address these gaps in holistic student development such as focus groups about their college adjustment and multiple identities. Such context-based intervention is important in an environment that has increased liability for college stressors (Constantine \& Greer, 2003; Grier-Reed, 2013; Rosales \& Person, 2004). As part of these interventions, it could also be beneficial for AfricanAmerican first-year students to recognize that their race-related stressors are part of larger societal systemic issues and not specific to them in order to minimize them from personalizing experiences of racial discrimination which could lead to high levels of depression and anxiety throughout their remaining college years. Predominantly white universities should be cognizant of the systemic, organizational, and structural issues that impact African-American students' well-being especially during a critical period of their development in which they are addressing major and also competing developmental tasks simultaneously (i.e. identity, interpersonal relationships, professional interests).

Future research in this area should use the results from the qualitative study to inform future quantitative analyses. Since student reported racial discrimination related to inter-group contact, a campus racial discrimination measure should have both face and 
content validity that reflects the specific type of racial discrimination that students stated in the focus groups (i.e. social experiences). Hence, such a racial discrimination should not have items related to racial discrimination committed by university professors/administrators. Also, it would be appropriate to test the quantitative hypotheses in a sample of African-American fourth year students, who, by the virtue of being at their university for a four-year period, may have more opportunities to encounter racial discrimination. The results might be consistent with the existing literature in the association between racial discrimination and mental health and the role of psychocultural factors. A focus group or exit interview about such experiences could also be conducted prior to their graduation in order to determine if students felt they were supported when encountering negative experiences and to identify potential areas to invest in supportive resources. Such qualitative can also be used to further corroborate the qualitative results that can serve to further extrapolate the details related to the findings. Additionally, longitudinal studies should be conducted to examine the changes in students' perceptions of racial discrimination, coping, resiliency, ethnic/racial identity, depression, anxiety, and somatic symptoms over the four years of college (e.g., Syed \& Azmitia, 2009).

The intersectionality theme that emerged in this study highlights that PWI's should also consider factors beyond race and ethnicity that are just as important to the college adjustment of African-American students. While the plethora of targeted services for African-American students at this institution may appear to serve as a protective factor for such students in a predominantly white university setting, students may feel inundated with inadvertent messages that only emphasize their racial identity, which may 
lead them to feel forced to identify with the African-American community. Instead, the institution can deliberately recognize the diversity across the African diaspora by having focused events and groups that reflect the diversity and intersecting identities of the African-American student body. It is important that such institutions support students' academic and personal development by avoiding indirect messages about AfricanAmerican students' perceptions of their racial and other identities. Such PWI's can integrate mental health services into the academic support services and culturally-relevant resources for first-year students through informal group discussions (i.e. AfricanAmerican men, Bi-/Multi-racial students, students from outside of the southeast geographic region, socioeconomic status) led by counseling center staff in a location outside of the counseling center. By implementing these types of interventions outside of university counseling, students may feel more apt to participate since it likely reduces the stigma of mental health. Since students did not disclose using mental health services as a resource to cope with their admitted transparency about academic, social, or race-related stressors in the focus groups, providing an informal psychotherapeutic space to discuss issues salient to diverse and developing first-year African-American students may be beneficial.

The present study emphasizes the importance of examining how one's environmental context can exacerbate their social-emotional functioning and psychological well-being. Beyond typical college stressors, African-American college students attending predominantly white universities are often faced with an additional layer of distress related to the campus climate and experiences of racial discrimination throughout their college transition and matriculation. Given the pervasiveness of racial 
discrimination and its often microaggressive nature, it is important that such institutions consider culturally sensitive ways to address issues related to diversity and inclusion as part of their mission of higher education and student development. Without a commitment to multicultural awareness and tolerance, predominantly white universities leave their African-American students vulnerable to psychological distress which can lead to decreased academic achievement and possibly withdrawal from college in these settings. By prioritizing and being intentional about providing relevant social supports and cultural connections, African-American students can be successful at predominantly white institutions despite academic and race-related stress. 


\section{References}

Aiken, L.S., \& West, S.G. (1991). Multiple Regression: Testing and Interpreting Interactions. Newbury Park, CA: Sage.

American Psychiatric Association, (2000). Diagnostic and Statistical Manual of Mental Disorders, Text Revision, 4th Edition. Washington, D.C.: American Psychiatric Association.

Ancis, J.R., Sedlacek, W. E., \& Mohr, J.J. (2000). Student perceptions of campus cultural climate by race. Journal of Counseling \& Development, 78, 180-185.

Arnett, J.J. (2000). Emerging adulthood: A theory of development from the late teens through the twenties. American Psychologist, 55, 469-480.

Awad, G. H. (2007). The role of racial identity, academic self-concept, and self-esteem in the prediction of academic outcomes for African American students. Journal of Black Psychology, 33, 188-207.

Baer, L., Jacobs, D.G., Meszler-Reizes, J., Blais, M., Fava, M., Kessler, R., ...O'Laughlin, J. (2000). Development of a brief screening instrument: The HANDS. Psychotherapy and Psychosomatics, 69, 35-41.

Baron, R.M., \& Kenny, D.A. (1986). The moderator-mediator variable distinction in social psychological research: Conceptual, strategic, and statistical consideration. Journal of Personality and Social Psychology, 51, 1173-1182. 
Black student college graduation rates remain low, but modest progress begins to show (2010). Journal of Blacks in Higher Education, 67. Retrieved December 5, 2011, from http://www.jbhe.com/features/50_blackstudent_gradrates.html

Borrell, L.N., Kiefe, C.I., Williams, D.R., Diez-Roux, A.V., \& Gordon-Larsen, P. (2006). Self-reported health, perceived racial discrimination, and skin color in African Americans in the CARDIA study. Social Science \& Medicine, 63, 14151427.

Branscombe, N.R., Schmitt, M. T., \& Harvey, R.D. (1999). Perceiving pervasive Discrimination among African Americans: Implications for group identification and well-being. Journal of Personality and Social Psychology, 77, 135-149.

Bronfenbrenner, U. (1979). The ecology of human development. Cambridge, MA: Harvard University Press.

Brown, D.L., \& Tylka, T.L. (2011). Racial discrimination and resilience in African American young adults: Examining racial socialization as a moderator. Journal of Black Psychology, 37, 259-285.

Brown, T., Williams, D., Jackson, J., Neighbors, H., Torres, M., Sellers, S., \& Brown, K. (2000). "Being black and feeling blue": The mental health consequences of racial discrimination. Race and Society, 2, 117-131

Cabrera, A.F., \& Nora, A. (1994). College students' perceptions of prejudice and discrimination and their feelings of alienation. Review of Education, Pedagogy, and Cultural Studies, 16, 387-409.

Cabrera, A.F., Nora, A., Terenzini, P.T., Pascarella, E., \& Hagedorn, L.S. (1999). Campus racial climate and the adjustment of students to college: A comparison 
between White students and African-American students. The Journal of Higher Education, 70, 134-160.

Carter, P.L. (2006). Intersecting identities: “Acting white,” gender, and academic achievement. In E.M. Horvat \& C. O’Connor (Eds.), Beyond acting white: Reframing the debate on black student achievement (pp. 111-132). United States: Rowman \& Littlefield Publishers.

Carroll, B.J. \& Davidson, J.R.T. (2000). Screening Scale for DSM-IV GAD Copyrighted. Case, A.D., \& Hunter, C.D. (2012). Counterspaces: A unit of analysis for understanding the role of settings in marginalized individuals' adaptive responses to oppression. American Journal of Community Psychology, 50, 257-270.

Cassidy, C., O'Connor, R.C., Howe, C., \& Warden, D. (2004). Perceived Discrimination and Psychological Distress: The Role of Personal and Ethnic Self-Esteem. Journal of Counseling Psychology, 51, 329-339.

Chao, R. C.-L., Mallinckrodt, B., \& Wei, M. (2012). Co-occurring presenting problems in African American college clients reporting racial discrimination distress. Professional Psychology: Research and Practice, 43, 199-207.

Clark, R., Anderson, N.B., Clark, V.R., \& Williams, D.R. (1999). Racism as a stressor for African Americans: A biopsychosocial model. American Psychologist, 54, 805-816.

Cole, E.R. (2009). Intersectionality and research in psychology. American Psychologist, 64, 170-180. 
Coleman, M.N., Chapman, S., \& Wang, D. C. (2013). An examination of color-blind racism and race-related stress among African American undergraduate students. Journal of Black Psychology, 39, 486-504.

Constantine, M.G., \& Greer, T.M. (2003). Personal, academic, and career counseling of African American women in college settings. New directions for Student Services, $140,41-51$.

Contrada, R.J., Ashmore, R.D., Gary, M.L., Coups, E., Egeth, J.D., Sewell, A., \&...Chasse, V. (2001). Measures of ethnicity-related stress: Psychometric properties, ethnic group differences, and associations with well-being. Journal of Applied Social Psychology, 31, 1775-1820.

Creswell, J.W. (2014). A concise introduction to mixed-methods research. Los Angeles: Sage Publications, Inc.: Los Angeles.

Cross, W. E. (1971). Negro to Black conversion experience: Towards a psychology of Black liberation. Black World, 20, 13-27.

D'Augelli, A.R., \& Hershberger, S.L. (1993). African American undergraduates on a predominantly White campus: Academic factors, social networks, and campus climate. Journal of Negro Education, 62, 67-81.

Deaux, K., Bikmen, N., Gilkes, A., Ventuneac, A., Joseph, Y., Payne, Y.A., \& Steele, C.M. (2007). Becoming American: Stereotype threat effects in Afro-Caribbean immigrant groups. Social Psychology Quarterly, 70, 384-404.

Dovidio, J.F., \& Gaertner, S.L. (1986). Prejudice, discrimination, and racism: Historical 
trends and contemporary approaches. In J. F. Dovidio \& S. L. Gaertner (Eds.), Prejudice, discrimination, and racism (pp. 1-34). San Diego, CA: Academic Press.

Eller, A. \& Abrams, D. (2004). Come together: Longitudinal comparisons of Pettigrew’s reformulated intergroup contact model and the Common Ingroup Identity Model in Anglo-French and Mexican-American contexts. European Journal of Social Psychology, 34, 229-256.

Ensel, W.M., \& Lin, N. (1991). The life stress paradigm and psychological distress. Journal of Health and Social Behavior, 32, 321-341.

Erikson, E.H. (1968). Identity: Youth and Crisis. New York: Norton.

Garcia Coll, C., Lamberty, G., Jenkins, R., McAdoo, H.P., Crnic, K., Wasik, B.H., \& Garcia, H.V. (1996). An integrative model for the study of developmental competencies in minority children. Child Development, 67, 1891-1914.

Gee, G.C., Ryan, A., Laflamme, D.J., \& Holt, J. (2006). Self-reported discrimination and mental health status among African descendants, Mexican Americans, and other Latinos in the New Hampshire REACH 2010 Initiative: The added dimension of immigration. American Journal of Public Health, 96, 1821-1828.

Gloria, A.M., Castellanos, J., \& Orozco, V. (2005). Perceived educational barriers, cultural fit, coping responses, and psychological well-being of Latina undergraduates. Hispanic Journal of Behavioral Sciences, 27, 161-183.

Greer, T.M., \& Brown, P. (2011). Minority status stress and coping processes among African American college students. Journal of Diversity in Higher Education, 4, 26-38. 
Greer, T.M., \& Chwalisz, K. (2007). Minority-related stressors and coping processes among African American college students. Journal of College Student Development, 48, 388-404.

Grier-Reed, T. (2010). The African American student network: Creating sanctuaries and counterspaces for coping with racial microaggressions in higher education settings. Journal of Humanistic Counseling, Education and Development, 49, 181-188.

Grier-Reed, T. (2013). The African American student network: An informal networking group as a therapeutic intervention for Black college students on a predominantly White campus. Journal of Black Psychology, 39, 169-184.

Harrell, S.P. (1994). The Racism and Life Experience Scale-Revised. Unpublished manuscript.

Hoffman, K., Llagas, C., \& Lopez, T.D. (2003). Status and trends in the education of Blacks. National Center for Education Statistics, NCES 2003-034.

Hughes, D. L., Johnson, D., Smith, E., Rodriguez, J., Stevenson, H. C., \& Spicer, P. (2006). Parents' ethnic/racial socialization practices: A review of research and directions for future study. Developmental Psychology, 42, 747-770.

Jackson J.S., Williams, D.R., \& Torres, M. (2003). Perceptions of discrimination and health: The social stress process. In A. Maney (Ed.), Social Stressors, Personal and Social Resources, and their Mental Health Consequences. Rockville, MD: National Institute of Mental Health. 
Jackson, J.S., Brown, T.B., Williams, D.R., Torres, M., Sellers, S.L., \& Brown, K. (1996). Racism and the physical and mental health status of African Americans: A thirteen-year national panel study. Ethnicity and Disease, 6, 132-147.

Jones, J.M. (1972). Prejudice and Racism. Menlo Park, CA: Addison-Wesley.

Joseph, N. \& Hunter, C.D. (2011). Ethnic-racial socializational messages in identity development of second-generation Haitians. Journal of Adolescent Research, 26, 344-380.

Kessler, R.C., Mickelson, K.D., \& Williams, D.R. (1999). The prevalence, distribution, and mental health correlates of perceived discrimination in the United States. Journal of Health and Social Behavior, 40, 208-230.

Kroeneke, K., Spitzer, R.L., \& Williams, J.B.W. (2002). The PHQ-15: Validity of a new measure for evaluating the severity of somatic symptoms. Psychosomatic Medicine, 64, 258-266.

Landrine, H., \& Klonoff, E.A. (1996). The schedule of racist events: A measure of racial discrimination and a study of its negative physical and mental health consequences. Journal of Black Psychology, 22, 144-168.

Lazarus, R., \& Folkman, S. (1984). Stress, appraisal, and coping. New York: Springer.

Lee Williams, J. \& Nichols, T.M. (2012). Black women's experiences with racial microaggressions: Making meaning at the crossroads of race and gender. In C.R. Chambers \& R.V. Sharpe (Eds.), Diversity and Higher Education, Volume 12, Black Female Undergraduates on College Campuses: Successes and Challenges (pp. 74-95) North America: Emerald. 
Matthews, D.D., Hammond, W.P., Nuru-Jeter, A., Cole-Lewis, Y., \& Melvin, T. (2013). Racial discrimination and depressive symptoms among African-American men: The mediating and moderating role of masculine self-reliance and John Henryism. Psychology of Men \& Masculinity, 14, 33-48.

McNeilly, M., Anderson, N.B., Armstead, C.A., Clark, R., Corbett, M.O., Robinson, E.L., \& Lepisto, E.M. (1996). The Perceived Racism Scale: A multidimensional assessment of the perception of White racism among African Americans. Racism and Health Ethnicity and Disease, 6, 154-166.

Mercer, S.H., Zeigler-Hill, V., Wallace, M., \& Hayes, D.M. (2011). Development and initial validation of the Inventory of Micro Aggressions Against Black Individuals. Journal of Counseling Psychology, 58, 457-469.

Neblett, E.W., Jr., Shelton, J.N., \& Sellers, R.M. (2004). The role of racial identity in managing daily racial hassles. In G. Philogene (Ed.), Racial identity in context: The legacy of Kenneth B. Clark. Washington, D.C: American Psychological Association Press.

O’ Connor, C. (1999). Race, class, and gender in America: Narratives of opportunity among low-income African American youths. Sociology of Education, 72, $137-$ 157.

Ong, A.D., Fuller-Rowell, T., \& Burrow, A.L. (2009). Racial discrimination and the stress process. Journal of Personality and Social Psychology, 96, 1259-1271.

Parker, M.N. \& Jones, R.T. (1999). Minority status stress: Effect on the psychological academic functioning of African-American students. Journal of Gender, Culture, and Health, 4, 61-82. 
Phinney, J.S. (1992). The Multigrain Ethnic Identity Measure: A new scale for use with diverse groups. Journal of Adolescent Research, 7, 156-176.

Phinney, J. S., \& Ong, A. D. (2007). Conceptualization and measurement of ethnic identity: Current status and future directions. Journal of Counseling Psychology, $54,271-281$.

Pieterse, A.L., \& Carter, R.T. (2007). An examination of the relationship between general life stress, racism-related stress, and psychological health among Black men. Journal of Counseling Psychology, 54, 101-109.

Ren, X.S., Amuck, B., \& Williams, D.R. (1999). Racial/Ethnic disparities in health: The interplay between discrimination and socioeconomic status. Ethnicity \& Health, 9, 151-165.

Rosales, A.M., \& Person, D.R. (2004). Programming needs and students services for African American women. In M.F. Howard-Hamilton (Ed.), Meeting the needs of African American women (pp. 53-65). San Francisco: Jossey-Bass.

Ryff, C. D., Keyes, C. L. M., \& Hughes, D. L. (2003). Status Inequalities, Perceived Discrimination, and Eudemonic Well-being: Do the Challenges of Minority Life Hone Purpose and Growth? Journal of Health and Social Behavior, 44, 275-291.

Sanders, M.G. (1994). Overcoming obstacles: Academic achievement as a response to racism and discrimination. The Journal of Negro Education, 66, 83-93.

Schofield, J. W., Hausmann, L. R. M., Ye, F., \& Woods, R. L. (2010). Intergroup friendships on campus: Predicting close and casual friendships between White and African American first-year college students. Group Processes \& Intergroup Relations, 13, 585-602. 
Schulz, A. J., Graveled, C. C., Williams, D. R., Israel, B. A., Metz, G., \& Rowe, Z. (2006). Discrimination, symptoms of depression, and self-rated health among African American women in Detroit: Results from a longitudinal analysis. American Journal of Public Health, 96, 1265-1270.

Sellers, R.M., Caldwell, C.H., Schmeelk-Cone, K.H., \& Zimmerman, M.A. (2003). Racial identity, racial discrimination, perceived stress, and psychological distress among African American young adults. Journal of Health and Social Behavior, $44,302-317$.

Sellers, R.M., Rowley, S.A.J., Chavous, T.M., Shelton, J.N., \& Smith, M.A. (1998). Multidimensional Model of Racial Identity: A reconceptualization of African American racial identity. Personality and Social Psychology Review, 2, 18-39.

Sellers, S. L., Bonham, V., Neighbors, H.W., \& Amell, J.W. (2009). Effects of racial discrimination and health behaviors on mental and physical health of middle-class African American men. Health Education \& Behavior, 36, 31-44.

Siefert, K., Finlayson, T.L., Williams, D.R., Delve, J., \& Ismail, A.I. (2009). Modifiable risk and protective factors for depressive symptoms in low-income African American mothers. American Journal of Orthopsychiatry, 77, 113-123.

Smedley, B.D., Myers, H.F., \& Harrell, S.P. (1993). Minority-status stresses and the college adjustment of ethnic minority freshmen. The Journal of Higher Education, 64, 434-452.

Smith, W. A., Allen, W. R., \& Danley, L. L. (2007). "Assume the position . . You fit the 
description": Campus racial climate and the psychoeducational experiences and racial battle fatigue among African American male college students. American Behavioral Scientist, 51, 551-578.

Smith, B.W., Dalen, J., Wiggins, K., Tooley, E., Christopher, P., \& Bernard, J. (2008). The Brief Resilience Scale: Assessing the ability to bounce back. International Journal of Behavioral Medicine, 15, 194-200.

Solórzano, D., Ceja, M., \& Yosso, T. (2000). Critical race theory, racial micro aggressions, and campus racial climate: The experiences of African American college students. Journal of Negro Education, 69, 60-73.

Stevenson, H. C. (1995). The relationship of racial socialization and racial identity in African American adolescents. Journal of Black Psychology, 21, 49-70.

Strauss, A., \& Corbin, J. M. (1990). Basics of qualitative research: Grounded theory procedures and techniques. Thousand Oaks, CA: Sage Publications.

Sue, D.W., Capodilupo, C.M., Torino, G.C., Bucceri, J.M., Holder, A.M.B., Nadal, K.L., \& Esquilin, M. (2007). Racial microaggressions in everyday life: Implications for clinical practice. American Psychologist, 62, 271-286.

Sue, D.W., Lin, A.I., Torino, G.C., Capodilupo, C.M., \& Rivera, D.P. (2009). Racial microaggressions and difficult dialogues on race in the classroom. Cultural Diversity and Ethnic Minority Psychology, 15, 183-190.

Syed, M., \& Azmitia, M. (2008). A narrative approach to ethnic identity in emerging adulthood: Bringing life to the identity status model. Developmental Psychology, 44, 1012-1027. 
Syed, M., \& Azmitia, M. (2009). Longitudinal trajectories of ethnic identity during the college years. Journal of Research on Adolescence, 19, 601-624.

Syed, M., \& Azmitia, M. (2010). Narrative and ethnic identity exploration: A longitudinal account of emerging adults' ethnicity-related experiences. Developmental Psychology, 46, 208-219.

Thompson, V.L.S. (1996). Perceived experiences of racism as stressful life events. Community Mental Health Journal, 32, 223-233.

Tinto, V. (1993). Leaving college: Rethinking the causes and cures of student attrition. Chicago: The University of Chicago Press.

Tormala, T. T., \& Deaux, K. (2006). Black immigrants to the United States: Confronting and constructing ethnicity and race. In R. Mahalingam (Ed.), Cultural psychology of immigrants (pp. 131-150). Mahwah, NJ: Lawrence Erlbaum.

Torres, L., Driscoll, M.W., \& Burrow, A.L. (2010). Racial microaggressions and psychological functioning among highly achieving African-Americans: A mixedmethods approach. Journal of Social and Clinical Psychology, 29, 1074-1099.

Umaña-Taylor, A. J., Quintana, S. M., Lee, R. M., Cross, W. E., Rivas-Drake, D., Schwartz, S. J.,...\& Study Group on Ethnic and Racial Identity in the $21^{\text {st }}$ Century (2014). Ethnic and racial identity revisited: An integrated conceptualization. Child Development, 85, 21-39.

Utsey, S. O., \& Ponterotto, J. G. (1996). Development and validation of the Index of Race-Related Stress (IRRS). Journal of Counseling Psychology, 43, 490-501.

Utsey, S.O., Giesbrecht, N., Hook, J., \& Stanard, P.M. (2008). Cultural, sociofamilial, and psychological resources that inhibit psychological distress in African 
Americans exposed to stressful life events and race-related stress. Journal of Counseling Psychology, 55, 49-62.

Watkins, D.C., Hudson, D. L., Caldwell, C. H., Siefert, K., \& Jackson, J.S. (2011). Discrimination, mastery, and depressive symptoms among African American men. Research on Social Work Practice, 21, 269-277.

Wei, M., Heppner, P. P., Ku, T.-Y., \& Liao, K. Y.-H. (2010). Racial discrimination stress, coping, and depressive symptoms among Asian Americans: A moderation analysis. Asian American Journal of Psychology, 1, 136-150.

Williams D.R. (2000). Race, stress, and mental health. In C. Hogue, M. Hargraves, \& K. Scott-Collins (Eds.), Minority Health in America. Baltimore, MD: Johns Hopkins University Press.

Williams, D.R. \& Chung, A. (2000). Racism and Health. In R. Gibson \& J. S. Jackson (Eds.), Health in Black America. Thousand Oaks, CA: Sage Publications.

Williams, D. R., \& Mohammed, S. A. (2009). Discrimination and racial disparities in health: Evidence and needed research. Journal of Behavioral Medicine, 32, 20-47.

Williams, D. R., \& Williams-Morris, R. (2000). Racism and mental health: The African American experience. Ethnicity \& Health, 5, 243-268.

Williams, D.R., Yu, Y., Jackson, J.S., \& Anderson, N.B. (1997). Racial differences in physical and mental health: Socioeconomic status, stress and discrimination. Journal of Health Psychology, 2, 335-351.

Witherspoon, K. M., Speight, S. L., \& Thomas, A. J. (1997). Racial identity attitudes, school achievement, and academic self-efficacy among African American high school students. Journal of Black Psychology, 23, 344-357. 
Wong, C.A., Eccles, J.S., \& Sameroff, A. (2003). The influence of ethnic discrimination and ethnic identification on African American adolescents' school and socioemotional adjustment. Journal of Personality, 71, 1197-1232. 


\section{Appendix A}

\section{Demographics}

1) Note: For the purpose of maintaining confidentiality, this information will be stripped from the remainder of your responses upon receipt and replaced with an ID number (NOT your University of Virginia ID or SSN). This demographic information will be kept in a separate file and used only for research purposes.

Name:

Local Address:

Address 2:

City/Town:

State:

Zip:

Email Computing I.D.:

Phone Number:

2) What is your gender?

_ Male

- Female

3) What is your birthdate?

Birthdate: MM/DD/YYYY

4) What is your current age?

5) How do you best describe your Black ethnicity/family ethnic origin (e.g. African American,

Jamaican, Nigerian, Bi/Multiethnic/racial (e.g. Jamaican and Puerto Rican)?

_ African (e.g. Nigeria, Ghana)

_ African-American (e.g. United States)

_ Caribbean (e.g. Jamaica, Haiti)

_ Latino/a (e.g. Mexico, Puerto Rico)

_ Bi/Multi-ethnic/racial (e.g. Black, Asian)

- Other

6) Please specify your BLACK ethnicity/family ethnic background(s) for your answer in \#5.

7) Please estimate your family's total yearly income.

under $\$ 10,000$ (\$0-\$192 per week)

_ $\$ 10,000$ - \$19,999 (\$193\$ - \$385 per week)

_ \$20,000-\$34,999 (\$386\$ - \$673 per week)

_ \$35,000-\$49,999 (\$674\$ - \$961 per week)

_ $\$ 50,000-\$ 64,999$ (\$962 - \$1,249 per week)

_ $\$ 65,000-\$ 79,999$ (\$1250\$ - \$1,538 per week) 
_ $\$ 80,000-\$ 99,999(\$ 1539 \$$ - $\$ 1,923$ per week)

_ $\$ 100,000$ or more (more than $\$ 1,923$ per week)

8) Are you the first person in your immediate family to attend a 4-year college/university?

Yes

No

9) What is the highest level of education completed by your MOTHER/maternal guardian?

$-9-11^{\text {th }}$ grade

- High school graduate

- Some college or Vocational/technical School

Associate's degree (2 year college)

Bachelor's degree

Master's degree

_ Doctoral degree (e.g. Ph.D., M.D., J.D.)

10) What is the highest level of education completed by your FATHER/paternal guardian?

$-9-11^{\text {th }}$ grade

_ High school graduate

_ Some college or Vocational/technical School

_ Associate's degree (2 year college)

Bachelor's degree

- Master's degree

_ Doctoral degree (e.g. Ph.D., M.D., J.D.) 


\section{Perceptions of Prejudice and Discrimination}

Think about your university and select the best answer that reflects how you feel.

\begin{tabular}{|l|l|l|l|l|l|}
\hline & $\begin{array}{l}1= \\
\text { Strong } \\
\text { Disagree }\end{array}$ & 2 & 3 & 4 & $\begin{array}{l}5= \\
\text { Strongly } \\
\text { Agree }\end{array}$ \\
\hline $\begin{array}{l}\text { I feel there is a general } \\
\text { atmosphere of prejudice } \\
\text { among students. }\end{array}$ & & & & & \\
\hline $\begin{array}{l}\text { I have observed } \\
\text { discriminatory words, } \\
\text { behaviors, or gestures directed } \\
\text { at minority students at this } \\
\text { institution. }\end{array}$ & & & & & \\
\hline $\begin{array}{l}\text { I have encountered racism } \\
\text { while attending this } \\
\text { institution. }\end{array}$ & & & & & \\
\hline $\begin{array}{l}\text { I have heard negative words } \\
\text { about people of my own race } \\
\text { or ethnicity while attending } \\
\text { classes. }\end{array}$ & & & & \\
\hline $\begin{array}{l}\text { I feel there is a general } \\
\text { atmosphere of prejudice } \\
\text { among faculty at this } \\
\text { institution. }\end{array}$ & & & & & \\
\hline $\begin{array}{l}\text { I feel there is a general } \\
\text { atmosphere of prejudice } \\
\text { among academic staff at this } \\
\text { institution. }\end{array}$ & & & & & \\
\hline $\begin{array}{l}\text { I have been discouraged from } \\
\text { participating in class } \\
\text { discussions. }\end{array}$ & & & & & \\
\hline $\begin{array}{l}\text { I have been singled out in } \\
\text { class and treated differently } \\
\text { than other students. }\end{array}$ & & & & \\
\hline
\end{tabular}




\section{List of Coping Resources}

Think about the times you have had a problem and how you have responded to it. Please read the following statements and indicate your level of agreement of the responses by selecting the number that best applies.

\begin{tabular}{|l|l|l|l|l|}
\hline & $\begin{array}{c}1=\text { Strong } \\
\text { Disagree }\end{array}$ & $\begin{array}{l}2= \\
\text { Disagree }\end{array}$ & $3=$ Agree & $\begin{array}{c}4=\text { Strongly } \\
\text { Agree }\end{array}$ \\
\hline $\begin{array}{l}\text { I try to actively find out } \\
\text { more about the situation } \\
\text { and I take some positive, } \\
\text { planned action. }\end{array}$ & & & & \\
\hline $\begin{array}{l}\text { I talk with others about } \\
\text { the problem (friends, } \\
\text { relatives) }\end{array}$ & & & & \\
\hline $\begin{array}{l}\text { I don't worry about it. } \\
\text { Everything will probably } \\
\text { work out for me. }\end{array}$ & & & & \\
\hline $\begin{array}{l}\text { I become involved in } \\
\text { other activities in order } \\
\text { to keep my mind off the } \\
\text { problem. }\end{array}$ & & & & \\
\hline $\begin{array}{l}\text { I pray and/or consult a } \\
\text { priest or a minister. }\end{array}$ & & & & \\
\hline $\begin{array}{l}\text { I seek professional } \\
\text { advice (physician, } \\
\text { psychologist, counselor) }\end{array}$ & & & & \\
\hline $\begin{array}{l}\text { I draw upon my past } \\
\text { experiences; perhaps } \\
\text { similar situations might } \\
\text { help. }\end{array}$ & & & & \\
\hline $\begin{array}{l}\text { I seek support from } \\
\text { members of my cultural } \\
\text { group. }\end{array}$ & & & & \\
\hline $\begin{array}{l}\text { I try to reduce tension } \\
\text { (e.g. drink, eat, drugs, } \\
\text { smoke, more exercise) }\end{array}$ & & & & \\
\hline $\begin{array}{l}\text { I think about how I can } \\
\text { best handle the situation } \\
\text { and act accordingly. }\end{array}$ & & & & \\
\hline
\end{tabular}




\section{Brief Resiliency Scale}

Please indicate the extent to which you agree with each of the following statements by using the following scale:

\begin{tabular}{|l|l|l|l|l|l|}
\hline & $1=$ Strong & $\begin{array}{l}2= \\
\text { Disagree }\end{array}$ & $3=$ Neutral & $4=$ Agree & $\begin{array}{l}5= \\
\text { Strongly } \\
\text { Agree }\end{array}$ \\
\hline $\begin{array}{l}\text { I tend to bounce } \\
\text { back quickly after } \\
\text { hard times. }\end{array}$ & & & & \\
\hline $\begin{array}{l}\text { I have a hard time } \\
\text { making it through } \\
\text { stressful events. }\end{array}$ & & & & & \\
\hline $\begin{array}{l}\text { It does not take } \\
\text { me long to } \\
\text { recover from a } \\
\text { stressful event. }\end{array}$ & & & & & \\
\hline $\begin{array}{l}\text { It is hard for me to } \\
\text { snap back when } \\
\text { something bad } \\
\text { happens. }\end{array}$ & & & & & \\
\hline $\begin{array}{l}\text { I usually come } \\
\text { through difficult } \\
\text { times with little } \\
\text { trouble. }\end{array}$ & & & & & \\
\hline $\begin{array}{l}\text { I tend to take a } \\
\text { long time to get } \\
\text { over set-backs in } \\
\text { my life. }\end{array}$ & & & & & \\
\hline
\end{tabular}


Multidimensional Inventory of Black Identity: Racial Group Centrality Subscale

\begin{tabular}{|l|l|l|l|l|l|l|l|}
\hline & $\begin{array}{l}1= \\
\text { Strong } \\
\text { Disagree }\end{array}$ & 2 & $\begin{array}{l}3= \\
\text { Neutral }\end{array}$ & 4 & 5 & 6 & $\begin{array}{l}7= \\
\text { Strongly } \\
\text { Agree }\end{array}$ \\
\hline $\begin{array}{l}\text { Overall, being } \\
\text { Black has very little } \\
\text { to do with how I } \\
\text { feel about myself. }\end{array}$ & & & & & & & \\
\hline $\begin{array}{l}\text { In general, being } \\
\text { Black is an } \\
\text { important part of } \\
\text { my self-image. }\end{array}$ & & & & & & & \\
\hline $\begin{array}{l}\text { My destiny is tied to } \\
\text { the destiny of other } \\
\text { Black people. }\end{array}$ & & & & & & & \\
\hline $\begin{array}{l}\text { Being Black is NOT } \\
\text { important to my } \\
\text { sense of what kind } \\
\text { of person I am. }\end{array}$ & & & & & & & \\
\hline $\begin{array}{l}\text { I have a strong } \\
\text { sense of belonging } \\
\text { to Black people. }\end{array}$ & & & & & & & \\
\hline $\begin{array}{l}\text { I have a strong } \\
\text { attachment to other } \\
\text { Black people. }\end{array}$ & & & & & & & \\
\hline $\begin{array}{l}\text { Being Black is an } \\
\text { important reflection } \\
\text { of who I am. }\end{array}$ & & & & & & & \\
\hline $\begin{array}{l}\text { Being Black is NOT } \\
\text { a major factor in my } \\
\text { social relationships. }\end{array}$ & & & & & & & \\
\hline
\end{tabular}




\section{Multigroup Ethnic Identity Measure-Revised}

In this country, there are many different words to describe the different backgrounds or ethnic groups that people come from. Some examples of the names of ethnic groups are Mexican American, African American, Japanese American, Jamaican, Asian American, Black, Puerto Rican, and White. Every person is born into an ethnic group, or sometimes more than one group, but people differ on how important their ethnicity is to them, how they feel about it, and how much their behavior is affected by it. These questions are about your ethnicity or your ethnic group and how you feel about it or react to it.

In terms of ethnic group, I consider myself to be:

\begin{tabular}{|l|l|l|l|l|l|}
\hline & $\begin{array}{c}1=\text { Strong } \\
\text { Disagree }\end{array}$ & $\begin{array}{l}2= \\
\text { Disagree }\end{array}$ & $3=$ Neutral & $4=$ Agree & $\begin{array}{l}5= \\
\text { Strongly } \\
\text { Agree }\end{array}$ \\
\hline $\begin{array}{l}\text { I have spent time } \\
\text { trying to find out } \\
\text { more about my ethnic } \\
\text { group, such as its } \\
\text { history, traditions, } \\
\text { and customs. }\end{array}$ & & & & \\
\hline $\begin{array}{l}\text { I have a strong sense } \\
\text { of belonging to my } \\
\text { own ethnic group. }\end{array}$ & & & & & \\
\hline $\begin{array}{l}\text { I understand pretty } \\
\text { well what my ethnic } \\
\text { group membership } \\
\text { means to me. }\end{array}$ & & & & & \\
\hline $\begin{array}{l}\text { I have often done } \\
\text { things that will help } \\
\text { me understand my } \\
\text { ethnic background } \\
\text { better. }\end{array}$ & & & & & \\
\hline $\begin{array}{l}\text { I have often talked to } \\
\text { other people in order } \\
\text { to learn more about } \\
\text { my ethnic group. }\end{array}$ & & & & & \\
\hline $\begin{array}{l}\text { I feel a strong } \\
\text { attachment towards } \\
\text { my own ethnic } \\
\text { group. }\end{array}$ & & & & & \\
\hline
\end{tabular}




\section{Carroll-Davidson Generalized Anxiety Disorder Screen}

These items refer to how you have been feeling on most days in the past 6 MONTHS:

\begin{tabular}{|l|l|l|}
\hline & Yes & No \\
\hline Most days I feel very nervous. & & \\
\hline Most days I worry about lots of things. & & \\
\hline Most days I cannot stop worrying. & & \\
\hline Most days my worry is hard to control. & & \\
\hline I feel restless, keyed up, or on edge. & & \\
\hline I get tired easily. & & \\
\hline I have trouble concentrating. & & \\
\hline I am easily annoyed or irritated. & & \\
\hline My muscles are tense and tight. & \\
\hline I have trouble sleeping. & \\
\hline $\begin{array}{l}\text { Did the things you noted above affect your daily life } \\
\text { (home life, work, or leisure) or cause you a lot of } \\
\text { distress? }\end{array}$ & & \\
\hline $\begin{array}{l}\text { Were the things you noted above bad enough that you } \\
\text { thought about getting help for them? }\end{array}$ & & \\
\hline
\end{tabular}




\section{Harvard Department of Psychiatry/National Depression Screening Day (HANDS)}

Over the past 2 WEEKS, how often have you:

\begin{tabular}{|l|l|l|l|l|}
\hline & $\begin{array}{l}\text { None or } \\
\text { little } \\
\text { of the } \\
\text { time }\end{array}$ & $\begin{array}{l}\text { Some } \\
\text { of } \\
\text { the time }\end{array}$ & $\begin{array}{l}\text { Most of } \\
\text { the time }\end{array}$ & $\begin{array}{l}\text { All of } \\
\text { the time }\end{array}$ \\
\hline Been feeling low in energy, slowed down? & & & & \\
\hline Been blaming yourself for things? & & & & \\
\hline Had a poor appetite? & & & & \\
\hline $\begin{array}{l}\text { Had difficulty falling asleep, staying } \\
\text { asleep? }\end{array}$ & & & & \\
\hline Been feeling hopeless about the future? & & & & \\
\hline Been feeling blue? & & & & \\
\hline Been feeling no interest in things? & & & & \\
\hline Had feelings of worthlessness? & & & & \\
\hline $\begin{array}{l}\text { Had difficulty concentrating or making } \\
\text { decisions? }\end{array}$ & & & & \\
\hline
\end{tabular}




\section{Patient Health Questionnaire Somatic Symptom Severity Scale (PHQ-15)}

During the past 4 WEEKS, how much have you been bothered by any of the following problems?

\begin{tabular}{|l|l|l|l|}
\hline & $\begin{array}{l}\text { Not bothered } \\
\text { at all/Not } \\
\text { applicable }\end{array}$ & $\begin{array}{l}\text { Bothered } \\
\text { a little } \\
\text { a lot }\end{array}$ & $\begin{array}{l}\text { Bothered } \\
\text { Stomach pain }\end{array}$ \\
\hline Back pain & & & \\
\hline Had a poor appetite? & & & \\
\hline Pain in your arms, legs, or joints (knees, hips, etc.) & & & \\
\hline Headaches & & & \\
\hline Chest pain/tension & & & \\
\hline Dizziness & & & \\
\hline Fainting spells & & & \\
\hline Feeling your heart pound or race & & & \\
\hline Pain or problems during sexual intercourse & & & \\
\hline Constipation, loose bowels, or diarrhea & & & \\
\hline Nausea, gas, or indigestion & & & \\
\hline Feeling tired or having low energy & & & \\
\hline Trouble sleeping & & & \\
\hline
\end{tabular}




\section{Appendix B}

\section{Focus Group Protocol Questions}

1) College can be a time of lots of fun and also many challenges, in thinking about your experiences at UVA, how do you deal with stressful situations?

2) When thinking about the academic aspect of this university, how do you deal with that stress?

3) Think about your social interactions and relationship with peers at college, how do you deal with that stress?

4) Now, think about what the climate is like. How would you describe it?

a. What is your perception about the campus climate in regards to race?

b. In general, how do you think African-Americans or Black students are treated at this university?

5) Have you been treated differently on campus because of your race or ethnicity?

a. What have been your specific experiences with racial or ethnic discrimination at this university (i.e., general vs. particular experiences)?

6) In thinking about your specific experiences of racial or ethnic discrimination at this university, how has these experiences with discrimination affected your psychological or emotional well-being? Physical health? How did you feel? Cope with? Deal with it?

a. Do you think that it's still affecting you mentally and physically?

7) In general, what ways do you cope with this racial or ethnic discrimination on campus?

a. What strategies do you use?

b. Do you use any campus resources to help you deal with it (e.g. Culturally Specific Offices/Departments, Residential Life, Student Organizations)?

8) Sometimes individuals manage discrimination by thinking about things specific such as their racial/ethnic history, family values, etc. to help them cope. How does your view of your race and/or ethnic identity influence your coping strategies with racial discrimination on campus?

a. Is there anything related to your culture or race that helps you to deal with discrimination on campus?

9) In thinking about your academics at this university, how has your academic stress/performance relate to your mental health functioning (e.g., psychological, emotional well-being, physical health)?

a. How do feel during these times?

b. How do u deal with it? 
10) Is there anything else that you want you want to share? 